\title{
Round-Robin Modelling of the Load-bearing Capacity of Slender Columns by Using Classical and Advanced Non- linear Numerical and Analytical Prediction Tools
}

\begin{abstract}
Alfred Strauss (D), Prof., Senior Scientist, Department of Civil Engineering and Natural Hazards, University of Natural Resources and Life Sciences, Vienna, Austria; Ana Mandić Ivanković, Prof., Senior Scientist, Department for Structural Engineering, University of Zagreb Faculty of Civil Engineering, Zagreb, Croatia; Vladimir Benko, Prof., Senior Scientist, Department of Concrete Structures and Bridges, Slovak University of Technology in Bratislava, Bratislava, Slowakei; José Matos (D), Prof., Senior Scientist, Institute for Sustainability and Innovation in Structural Engineering (ISISE), University of Minho, Braga, Portugal; Pierre Marchand, Dr, Scientist, MAST-EMGCU, Univ Gustave Eiffel, IFSTTAR, Marne-la-Vallée, France; Roman Wan-Wendner (D, Prof., Senior Scientist, University of Natural Resources and Life Sciences, Vienna, Austria; Ghent University, Ghent, Belgium; Neryvaldo Galvão, PhD, Institute for Sustainability and Innovation in Structural Engineering (ISISE), University of Minho, Braga, Portugal; André Orcesi, Dr, Senior Scientist, MAST-EMGCU, Univ Gustave Eiffel, IFSTTAR, Marne-la-Vallée, France; Jakub Dobrý, PhD, Department of Concrete Structures and Bridges, Slovak University of Technology in Bratislava, Bratislava, Slowakei; Mohammad El Hajj Diab, Dr, Scientist, MAST-EMGCU, Univ Gustave Eiffel, IFSTTAR, Marne-la-Vallée, France; Krešimir Ninčević, PhD; Michael Hauser, PhD, Department of Civil Engineering and Natural Hazards, University of Natural Resources and Life Sciences, Vienna, Austria; Mladen Srbić, PhD; Dominik Skokandić, Dr, Scientist, Department for Structural Engineering, University of Zagreb Faculty of Civil Engineering, Zagreb, Croatia. Contact: alfred.strauss@boku.ac.at

DOI: $10.1080 / 10168664.2020 .1740069$
\end{abstract}

\begin{abstract}
Non-linear finite element analyses have intrinsic model and user factors that influence the results of the analyses. However, non-linear finite element analysis can provide a tool to assess safety using realistic descriptions of material behaviour with actual material properties. A realistic estimation of the existing safety and capacity of slender column elements can be achieved by means of "true" material properties. Nevertheless, it seems that for some structural components, such as slender columns, non-linear finite element analyses can, due to its complexity and its various setting parameters, cause the risk of overestimating the real performance of analysed components or systems. Hence, an invited expert group has carried out an investigation into the experimental testing and the prediction of the bearing capacity of slender columns by performing independent non-linear finite element analyses in order to determine the practical applicability, and its inconsistencies, with respect to the stability failure of slender columns. This work aims the characterization of modelling uncertainties, concerning the prediction of slender columns stability when forecasted by non-linear finite element analysis.
\end{abstract}

Keywords: non-linear finite element analyses; slender column elements; model and modelling uncertain tests; round-robin modelling tests

\section{Introduction}

Non-linear calculation methods allow realistic prediction of the load-deformation curve of a reinforced concrete structure given the non-linear stressstrain relationship of the concrete and steel reinforcement ${ }^{1-3}$ and enable an accurate design in the ultimate and serviceability limit states when compared to other proven approximations methods such as the moment magnification procedure according to ACI 318-14. However, geometrical and mathematical nonlinear design of slender members, such as columns in the ultimate limit state, is still a matter of controversy because of the known inconsistencies in the design concept. Therefore, despite the explicit possibilities in $\mathrm{EN}$ 1992-1-1 of using non-linear methods, there is still a need for research. This investigation focuses on an a priori collaborative round-robin test of numerical simulations to predict the load capacity of slender single columns with respect to a posteriori experimental series. ${ }^{4}$ The results show, on the one hand, that the nonlinear numerical calculations clearly overestimate the load-bearing capacity of the slender columns in some cases, and on the other hand, that the current design code proposed approximation methods, e.g. the nominal curvature-based method, provide results which are too conservative. In the future, the development of generally applicable and consistent proof formats for non-linear calculations ${ }^{5}$ will be necessary, along with providing the users of the available software packages with "best practice" guidelines for safe use. Nonlinear calculations were compared with a series of experimentally verified slender columns. ${ }^{4,6-9}$

\section{State of the Art "Design of Slender Columns"}

EN 1992-1-1 ${ }^{10}$ includes the general method (\$5.8.6), the procedure with nominal stiffness (\$5.8.7) and the method with nominal curvatures (\$5.8.8) hence basically providing three verification methods for the design of slender compressive elements. We believe the results with these three methods should be compared with those proposed in this paper. The general procedure is based on a non-linear system theory. The simplified nominal curvature method and the simplified nominal stiffness method account for the theory and for the non-linear effects, either by a computational reduction in system bending-stiffness rating or by a computational increase of the moment based on an estimated bending maximum- 
curvature in the relevant cross-section. These proximity techniques are well accepted, allow safe use, and provide satisfying results within the intended range of applications. However, with very slender columns, the nominal curvature method sometimes results in a very conservative design due to the simplicity of the application, in particular for large eccentricity. ${ }^{11}$ Generally, scientists resort to the so-called general procedure for slender aesthetic structural pillars and bridge piers, despite the widespread availability of powerful calculation programmes. For a description of the realistic relationship between compressive stress and strain of the concrete, a rational function calibrated on pressure tests and based on mean values is given in EN 1992-1-1, point 3.1.5, which is applicable to non-linear methods both for ultimate and serviceability limit states. In particular, the mean value of the concrete compressive strength is reduced to the design value and the mean value of the modulus of elasticity, defined as a secant modulus, is reduced by the factor $\gamma_{c E}=1.2$. It should take into account the direct determination of additional moments from secondorder theory and the beneficial effects of concrete tension stiffening or the appropriate procedures for the adverse effects of creep under longterm loading. The determination of the ultimate limit state and practically applicable methods for the consideration of the tensile stiffening in EN 1992-1-1 will not be discussed in detail here, more insight can be found in the relevant literature. ${ }^{12,13}$ In this context, it should be noted that DIN EN 1992-1-1 ${ }^{10}$ is based on so-called calculation values of the material properties which should provide more consistent results in non-linear system calculations as well as with regard to the probabilistic calculations. It is more consistent and respects the terms of the Eurocode underlying safety concept. ${ }^{4,14}$ The aforementioned modifications of the modulus of elasticity in case of very slender columns leads to large additional moments due to second-order effects and to a significant reduction in the bearing capacity. The method proposed by Quast, ${ }^{13}$ and reintroduced in DIN EN 1992-1$1,{ }^{10}$ for the determination of internal forces by means of reduced mean values is recommended as an alternative with respect to the general procedure. However, the actual design takes place in a second step at the cross-sectional level. This method gives good results, but only partially pursues the principles of the generally valid semi-probabilistic safety concept. Principles and different approaches in non-linear calculations found in Austrian annex, German code and Eurocode were analysed and can be found in Ref. [15].

\section{Modelling and Test Series of Columns}

\section{Objectives}

Non-linear finite element analyses are becoming increasingly interesting for the structural assessment and life cycle assessment of existing reinforced concrete structures. ${ }^{16,17}$ This fact has recently been discussed in relevant technical committees and experts have developed application rules and recommendations for non-linear analyses as well as for the related safety formats. ${ }^{18,19}$ Many of the non-linear FEM software products are based on sophisticated models of fracture mechanics, such as combined fracture plasticity models, orthotropic smeared crack formulations, rip band models, hardening / -softening plasticity models, and complex solution algorithms, such as the integration of complex constitutive equations. A meaningful non-linear FEM analysis, therefore, requires the user to have a basic knowledge of material models, solution algorithms, choosing the appropriate boundary conditions (bearing and supporting conditions, idealization of load cases - its properties and its combination, incremental loading procedure) and selecting the appropriate finite element type and meshing associated with the considered structural system or detail. ${ }^{6}$ For realistic modelling and proper fulfillment of the above requirements, it is common practice that calibrations of the non-linear finite element models are performed on already tested systems before they are applied to real structures in an adapted manner.

The IABSE Task group 1.4 under auspices of the IABSE Commission 1 (Performance and Requirements) carried out a study to predict the safety level and the capacity of slender compressive elements in relation to the non-linear FEM analyses. In particular, the questions addressed were to what extent the non-linear FEM analyses allow (a) a reliable prediction of the $N-M$ interaction pathways, (b) an assessment of the actual safety level and (c) the assessment of the modelling uncertainties. In the run-up to a test campaign of slender columns in the laboratories of the University of Bratislava, ten institutions from the University and industrial sectors with experience in nonlinear finite element modelling were invited to predict the performance of the columns by using non-linear modelling techniques. In the first phase, the experts were informed about the classical reinforcement plans and formwork plans as well as the standard material specifications of the concrete and reinforcing steel. For modelling, the initial eccentricity $e_{1}$, which was predefined for the experimental setup, as well as the storage conditions of the columns, were announced. The load-deformation curves and $N-M$ paths obtained from the modelling were collected and evaluated in a common diagram. In the second phase, the experts were provided with more detailed information on the material properties of the materials obtained during the test procedure and information on the test setup. In the third phase, the records of the monitoring systems were made available during the test procedure. This step-by-step provision of information is instrumental in model uncertainty and subsequent results, and shows some correlation to the information available in practice during design, execution- and monitoring.

\section{Initial Design}

The first task in planning the test campaign was to properly design the crosssectional geometry and the reinforcement layout of the columns, and to determine the initial eccentricity of the axial force to achieve the desired column system stability failure. The major objective of this task was to design the slender column according to the Eurocode standard, while the design has to show a stability failure before reaching the pre-defined $N-M$ interaction diagram. The $N-M$ load path has to end in front of the interaction diagram and the cross-section compressive strain has to be far away from its ultimate strain capacity. The final layout, as presented in Fig. 2, shows a system stability failure with a cross-section compressive strain of $\varepsilon_{c 1}$ $=1.5 \%$, see also, ${ }^{13}$ which is far away from threshold of $\varepsilon_{c u}=3.5 \%$ (Fig. 1). 


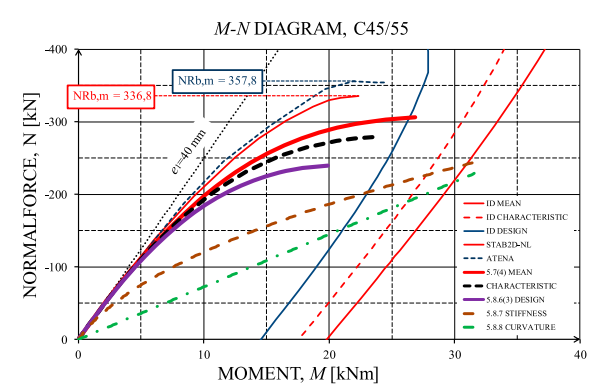

Fig. 1: Non-linear finite element optimization procedures for the C45/55 column
The University of Bratislava used nonlinear finite element calculations ${ }^{13}$ for this column design, in particular for the determination of the maximum normal force $N_{\max }$ and the initial eccentricity $e_{1}$ causing the stability failure. For these non-linear finite element calculations, the University of Bratislava used the standard properties of the concrete C45/55 and the reinforcement B500B. Further information can be found in Ref. [4].
The columns have a rectangular crosssection with a width $b=240 \mathrm{~mm}$, a depth $t=150 \mathrm{~mm}$ and a length $l=$ $3840 \mathrm{~mm}$ inclusive of the load introduction plates $(t=20 \mathrm{~mm})$ at the top and bottom of the columns. The columns are reinforced with four bars, $\varnothing 14 \mathrm{~mm}$ in diameter. These four bars are supplemented with another four bars with diameter of $\varnothing 14 \mathrm{~mm}$ and length of $600 \mathrm{~mm}$ on both ends of the columns. The supplementary bars are

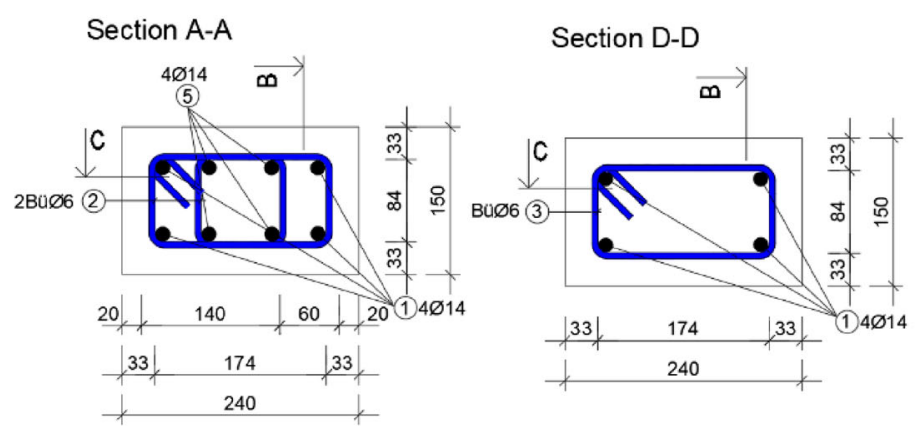

\begin{tabular}{|c|c|c|c|c|c|c|c|}
\hline \multirow{2}{*}{$\begin{array}{l}\text { BAR } \\
\text { NUMBER }\end{array}$} & \multirow{2}{*}{\multicolumn{2}{|c|}{$\begin{array}{l}\text { DIAMETER OF } \\
\text { BAR } \\
\varnothing[\mathrm{mm}]\end{array}$}} & \multirow{2}{*}{$\begin{array}{l}\text { LENGTH } \\
\text { OF BAR } \\
{[\mathrm{m}]}\end{array}$} & \multirow{2}{*}{$\begin{array}{l}\text { AMOUNT } \\
\text { OF BAR } \\
\text { [m] }\end{array}$} & \multicolumn{3}{|c|}{ OVERALL LENGTH [m] } \\
\hline & & & & & $\varnothing 6$ & $\varnothing 10$ & $\varnothing 14$ \\
\hline 1 & & 14 & 3,80 & 4 & & & 15,20 \\
\hline 2 & & 6 & 0,64 & 56 & 35,84 & & \\
\hline 3 & & 6 & 0,76 & 18 & 13,68 & & \\
\hline 4 & & 10 & 0,84 & 2 & & 1,68 & \\
\hline 5 & & 14 & 0,60 & 8 & & & 4,80 \\
\hline \multirow{4}{*}{\multicolumn{2}{|c|}{ SUMMARIZED }} & \multicolumn{3}{|c|}{ LENGTH [m] } & 49,52 & 1,68 & 20,00 \\
\hline & & \multicolumn{3}{|c|}{ WEIGHT $[\mathrm{kg} / \mathrm{m}]$} & 0,222 & 0,617 & 1,208 \\
\hline & & \multicolumn{3}{|c|}{ WEIGHT [kg] } & 10,99 & 1,04 & 24,16 \\
\hline & & \multicolumn{3}{|c|}{ WEIGHT [kg] } & \multicolumn{3}{|c|}{36,19} \\
\hline
\end{tabular}

CONCRETE: $0,137 \mathrm{~m}^{3}$
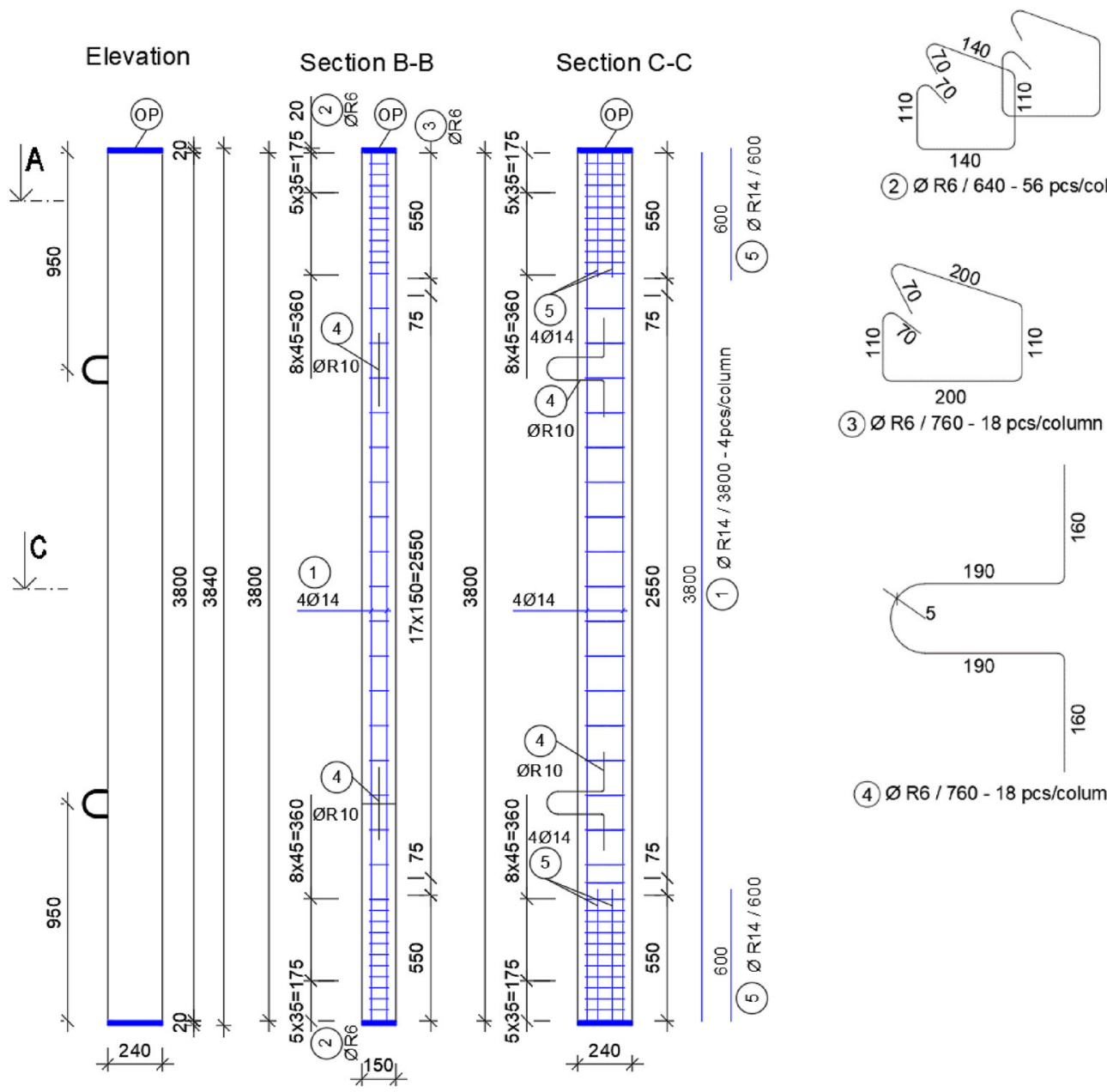

(2) $\oslash R 6 / 640$ - 56 pcs/column

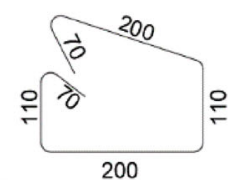

(3) $\varnothing \mathrm{R} 6 / 760-18 \mathrm{pcs} / \mathrm{column}$

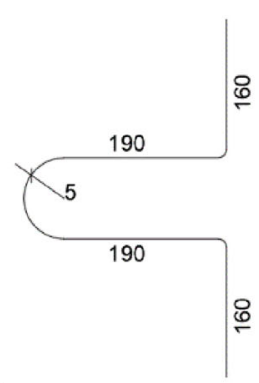

(4) $\varnothing \mathrm{R} 6$ / 760 - $18 \mathrm{pcs} / \mathrm{column}$

Fig. 2: Reinforcement and formwork plans of the investigated slender columns 
welded to $20 \mathrm{~mm}$ thick steel plates. The transverse reinforcement consists of two leg stirrups with diameter of $\varnothing$ $6 \mathrm{~mm}$. As the local failure in the ending parts can precede the stability collapse of the columns, the resistance is increased by doubling the transverse reinforcement along the length of the additional bars. The geometry and the reinforcement of columns are presented in Fig. 2. The reinforced concrete columns are prefabricated elements with predefined production tolerances and a concrete cover of $c_{\text {nom }}=20 \mathrm{~mm}$. The concrete cover was guaranteed by spacers to be mounted on the reinforcement cage.

\section{Initial Capacity Prediction}

In a first round, before the invitation of the IABSE expert group, Bratislava University invited service providers in the field of non-linear finite element modelling to make a prognosis of the expected test results of the slender columns described above. The detailed information about the invited instiused can be found in Ref. [7]. In addition to the characteristic values of the column stability failures, the invited institutions provided the $N-M$ allowed a deeper insight into the system responses during the loading process and thus into the initiation or change of fracture processes, where $e_{2}=$ displacement normal to the longitudinal axis in midspan of the column. The associated $\mathrm{N}-e_{2}$ graphs in Ref. [4] showed the linear elastic regions, the first-crack formations, the fracturedominated regions and the softeningspecific regions. These analyses allowed a first characterization of the model or modelling uncertainties in tutions and the software products interaction and the $N-e_{2}$ curves which

the respective stress areas. Consequently, these initial studies provided the basis for the requests sent to the IABSE members in the follow-up.

\section{Test Series of Columns}

The experimental procedure on the test specimens denoted S1-1 to S1-6 was divided into two groups: (a) group I comprised the columns S1-1 to S1-3 which were loaded at $e_{1}=$ $+40 \mathrm{~mm}$ closer to those column surfaces that were closer to the floor during casting, see Fig. 3; and (b) group II comprised the columns $\mathrm{S} 1-4$ to S1-6 which were loaded at $e_{1}=$ $-40 \mathrm{~mm}$ closer to those column surfaces that were closer to the filling opening during casting.

The monitoring set-up considered for this experimental campaign is shown in Fig. 4. This figure presents the arrangement of the LVDT sensors at the surfaces at half the height of the slender columns with a measuring distance $l_{0}=300 \mathrm{~mm}$. The values measured on the compressed side were as follows: $e_{2}$ - second-order eccentricity, TP1 and TP2 - compressive strain in the concrete and D1 - distance from the chosen base. On the side in tension these values were measured: E2 - second-order eccentricity, TP3 and TP4 - strain of concrete and D2 - distance from the chosen base.

The results from the six tested columns, which comprised the maximum load capacity $N_{\max }$, the displacement $e_{2}$ normal to the column longitudinal axis at the $N_{\max }$ load level and the associated bending moment $M_{\max }$ are presented in Table 1. It is observed that the maximum load capacity $N_{\max }$ of group I shows significant higher
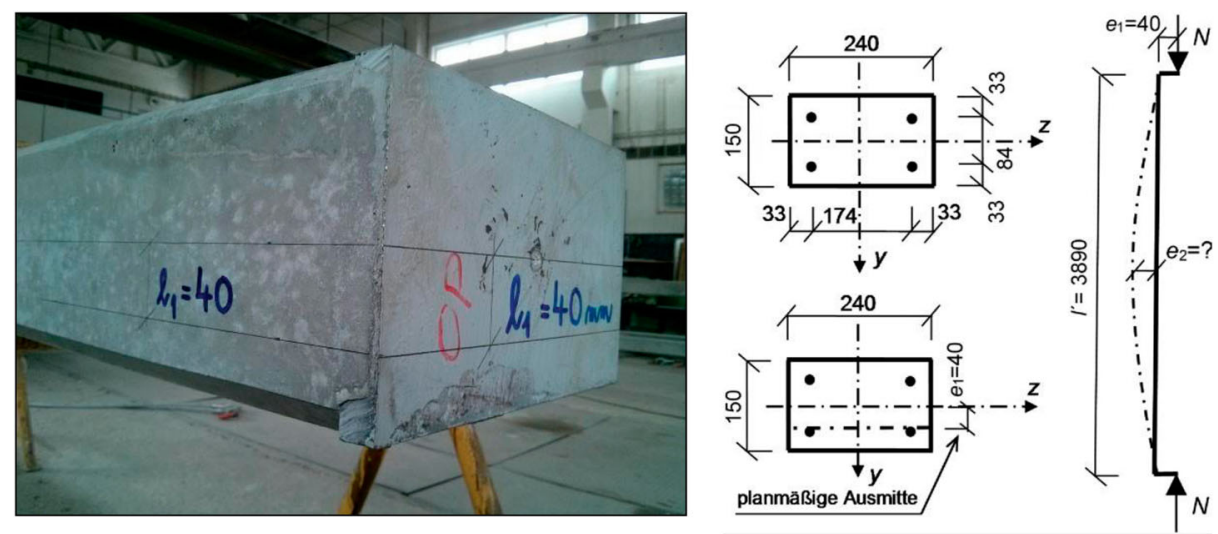

Fig. 3: Column test specimen from C45/55 and a load eccentricity $\mathrm{e}_{1}=+40 \mathrm{~mm}$, optimised for stability failure

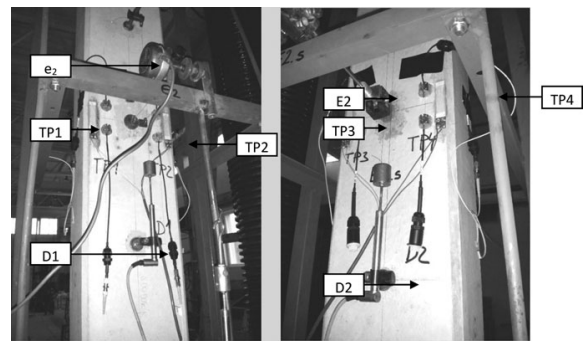

Fig. 4: Monitoring set up and sensor positions of the investigated slender columns

values and a different $N$ - $M$ interaction performance compared to group II. The points shown in Fig. 5 represent the tested maximum normal force load capacity $N_{\max }$ of each single column. Some of these points show the system stability failure before the $N-M$ interaction threshold as defined in EN 1992-1-1. ${ }^{10}$ The right-hand graphic of Fig. 5 shows the load-vsstrain graphs in the fracture-prone cross-section at half the height of the columns. The concrete compressive strains in the inner fibre of the crosssection were recorded for the column stability loss between 1.4 and 1.8\%o, and were far away from the permissible concrete compressive strains of $3.5 \%$. The associated concrete/reinforcement tension strains in the outer fibre of the cross-section were recorded between 1.4 and $3.1 \%$, see Fig. 5 .

A more detailed analysis of the recorded data of the monitoring system and the test machine disclosed that the differences between group I and group II columns as presented in Table 2 did not result from the monitoring set-up nor from the machinespecific properties but rather from the manufacturing processes of the columns. The analyses of the concrete homogeneity and the fracture properties in the column cross-sections at half of the column heights (in the area of the Monitoring Set Up) finally allowed the conclusion that the concreting direction, despite a good concrete vibration, causes an inhomogeneity in the cross-section of the material properties such that, in consequence, the loading location $e_{1}$ $=+40 \mathrm{~mm}$ or $e_{1}=-40 \mathrm{~mm}$ causes a significant difference in the associated load capacity $N_{\max }$. Finally, the model uncertainties of the experimental test results could be derived according to the EN 1992-1 ${ }^{10}$ methods with $\theta_{N \max }$ $=N_{\text {max } \text { mean }(\text { Serie I) }} / N_{\text {max }}$, mean $=1.06$ for the load capacity, with $\theta_{e 2, N \max }=e_{2}$, $N$ max,mean(Serie I) $/ e_{2, N m a x,}$ mean $=1.02$ for the horizontal deformation and 


\begin{tabular}{|l|l|l|l|l|}
\hline Group & \multicolumn{1}{|c|}{ Test } & $\boldsymbol{N m a x}[\mathbf{k N}]$ & $\boldsymbol{e}_{\mathbf{2}}[\mathbf{m m}]$ & $\boldsymbol{M} \mathbf{m a x}[\mathbf{k N m}]$ \\
\hline I & S1-1 & 324.4 & 57.6 & 31.7 \\
\hline I & S1-2 & 323.4 & 42.7 & 26.8 \\
\hline I & S1-3 & 332.6 & 38.3 & 26.0 \\
\hline II & S1-4 & 271.2 & 58.4 & 26.7 \\
\hline II & S1-5 & 296.0 & 59.4 & 29.4 \\
\hline II & S1-6 & 311.4 & 55.0 & 29.6 \\
\hline & S1-1 to S1-3 & $326.8(0.02)$ & $46.2(0.22)$ & $28.2(0.11)$ \\
\hline & S1-4 to S1-6 & $292.9(0.07)$ & $57.6(0.04)$ & $28.6(0.06)$ \\
\hline & S1-1 to S1-6 & $309.8(0.07)$ & $51.9(0.17)$ & $28.4(0.08)$ \\
\hline
\end{tabular}

Note: Values in brackets represent the Coefficients of Variation.

Table 1: Descriptive statistical parameters of the experimental results of the considered test series C45/55 without considering sample size aspects

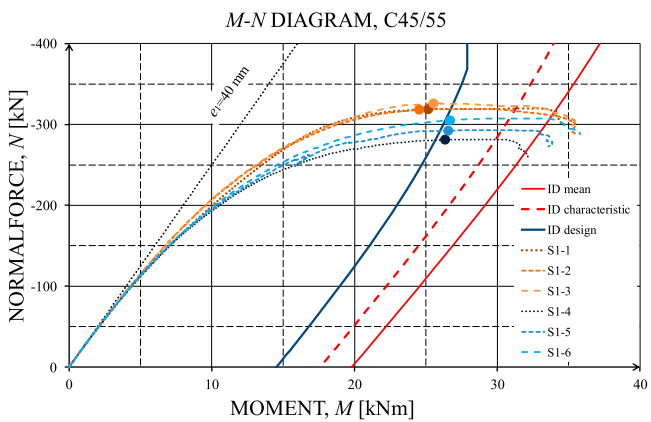

Fig. 5: By testing determined interaction between normal force - bending moment and normal force - strain of the specimens S1-1 to S1-6 vs. the N-M section interaction diagram (blue graph $=$ design values, red dashed graph $=$ characteristic values, red graph $=$ mean values) ${ }^{6}$

with $\theta_{M, N \max }=\theta_{M, N \max , \text { mean }(\text { Serie I) }} / \theta_{M}$, Nmax, mean $=1.01$ for the moments at the load level of the load capacity $N_{\max }$.

\section{Small Specimens Conformity Tests}

\section{Tests-Information for NL-FEM Modelling}

In addition to the column tests, concrete conformity tests were also carried out. Associated results were subsequently provided after the first NLFEM prediction round as additional information for the nonlinear modelling (see the section Round-Robin Modelling Posed Data and Questions for further details on the NLFEM information provision procedure). In general, the properties of concrete are characterized via the compressive strength according to EN $206-1,{ }^{20}$ the exposure classes and the slump value. Nevertheless, any realistic modelling of structures requires the

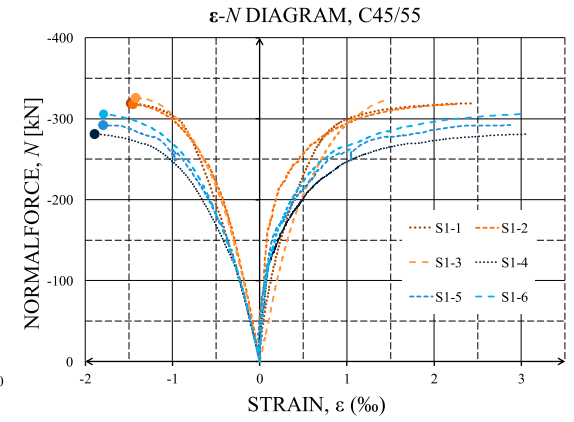

the course of the investigations. The experiments enabled a partially redundant identification of the material properties mentioned above beyond the code information.

Table 2 shows the detailed results of the cube compression tests, cylinder compression tests and three-point bending tests according to EN206-1 ${ }^{20}$ for the small scale specimens of column $\mathrm{C} 45 / 55$ which were considered from the partners in the $2^{\text {nd }}$ modelling round. Table 5 shows the detailed results of the Cube compression tests, cylinder compression tests and threepoint bending tests according to EN206- $1^{20}$ for the small scale specimens of column C100/115.

\section{Compression Test}

In order to determine the compressive strength according to EN 12390-3, test cubes of the investigated concrete type C45/55 and C100/115 (see Tables 2 and 3) with the dimensions $150 / 150 / 150 \mathrm{~mm}$ were loaded with a gradual increase of the stress level starting with 0.5 up to $0.8 \mathrm{MPa} / \mathrm{s}$ until the maximum load was reached. The maximum load was defined as that test load at which an increase within a period of $4 \mathrm{~s}$ was no longer possible.

The first set of cubes of series C45/55 and of series C100/115 were tested after 7 days of immersion in water and 21 days of exposure to air at an average air humidity of $60 \%$ and an air temperature of $21^{\circ} \mathrm{C}$, see Table 3 .

consideration of (a) geometrical nonlinear effects (when relevant) and non-linear behaviour of concrete (usually referred to as fracture-mechanical parameters) which can be captured by e.g. a varying modulus of elasticity $E_{c}$ (according to the stress levels), tensile strength $f_{t}$ and specific fracture energy $G_{f}{ }^{21}$ and (b) of random uncertainties in material and geometrical properties caused by (among other things) natural effects, manufacturing processes and curing. ${ }^{22}$ These requirements together with the newly characterized concrete classes in the Eurocode concept gave rise to the experimental investigations with the concrete C45/55 and C100/115, as used for the discussed columns, according to EN 206-1 or ÖNORM B 4710$1^{23}$ In particular, the standardized compression test (EN 12390-3), ${ }^{24}$ the standardized three-point bending test of notched specimens (EN 14651) $)^{25}$ and the wedge-splitting test (ÖNORM B 3592) ${ }^{26}$ were applied in
The second set of cubes of series $\mathrm{C} 45$ / 55 and of series C100/115 were tested after 103 days. The examinations of the Series 2 test cubes were conducted under similar storage and exposure conditions as Series 1, see Table 3. A similar testing campaign as on cubes $150 \mathrm{~mm} / 150 \mathrm{~mm} / 150 \mathrm{~mm}$ had also been performed on cylinders with a diameter of $150 \mathrm{~mm}$ and a height of $300 \mathrm{~mm}$, see Tables 2 and 3. The results of these comprehensive compression testing campaigns are presented in Tables 2 and 3 and were provided to the modelling expert group after their first simulation results, see the section Three-Point Bending Fracture Test.

\section{Three-Point Bending Fracture Test}

One of the typical tests to obtain material parameters, and fracture parameters, in particular, is the fracture test of specimens with a central edge 


\begin{tabular}{|c|c|c|c|c|c|}
\hline $\begin{array}{l}\text { Cube } 150 \times 150 \times 150 \mathrm{~mm} \\
\text { number }\end{array}$ & $\begin{array}{c}\text { Age } \\
{[\text { day }]}\end{array}$ & $\begin{array}{l}\text { Density } \\
{\left[\mathrm{kg} / \mathrm{m}^{3}\right]}\end{array}$ & $\begin{array}{c}\text { Failure load } \\
F_{\max }[\mathrm{N}] \\
\end{array}$ & \multicolumn{2}{|c|}{ Compressive strength [MPa] } \\
\hline 1 & 28 & $2410 \pm 10$ & 1455.3 & 64.0 & $64.0 \pm 0.8$ \\
\hline 2 & 28 & $2410 \pm 10$ & 1467.6 & 64.7 & $64.7 \pm 0.8$ \\
\hline 3 & 28 & $2410 \pm 10$ & 1514.5 & 66.6 & $66.6 \pm 0.8$ \\
\hline 4 & 28 & $2410 \pm 10$ & 1434.3 & 62.9 & $62.9 \pm 0.8$ \\
\hline 5 & 28 & $2410 \pm 10$ & 1456.2 & 64.1 & $64.1 \pm 0.8$ \\
\hline 6 & 28 & $2410 \pm 10$ & 1545.4 & 68.5 & $68.5 \pm 0.8$ \\
\hline 7 & 103 & $2380 \pm 10$ & 1690.7 & 74.7 & $74.7 \pm 0.9$ \\
\hline 8 & 103 & $2370 \pm 10$ & 1632.0 & 72.1 & $72.1 \pm 0.9$ \\
\hline 9 & 103 & $2370 \pm 10$ & 1665.8 & 73.9 & $73.9 \pm 0.9$ \\
\hline 10 & 103 & $2380 \pm 10$ & 1693.4 & 74.7 & $74.7 \pm 0.9$ \\
\hline 11 & 103 & $2380 \pm 10$ & 1625.2 & 72.2 & $72.2 \pm 0.9$ \\
\hline \multirow[t]{2}{*}{12} & 103 & $2380 \pm 10$ & 1704.6 & 75.4 & $75.4 \pm 0.9$ \\
\hline & & & & \multicolumn{2}{|c|}{ Rounded to 0.1MPa + U } \\
\hline $\begin{array}{l}\text { Cylinder } \phi 150 \times 300 \mathrm{~mm} \\
\text { number }\end{array}$ & $\begin{array}{c}\text { Age } \\
{[\text { day }]}\end{array}$ & $\begin{array}{l}\text { Density } \\
{\left[\mathrm{kg} / \mathrm{m}^{3}\right]}\end{array}$ & $\begin{array}{c}\text { Failure load } \\
F_{\max }[\mathrm{N}] \\
\end{array}$ & $\begin{array}{c}\text { Compressive strength } \\
{[\mathrm{MPa}]} \\
\end{array}$ & \\
\hline 1 & 28 & $2420 \pm 20$ & 980.7 & 54.6 & $54.6 \pm 0.8$ \\
\hline 2 & 28 & $2400 \pm 20$ & 946.7 & 52.4 & $52.4 \pm 0.8$ \\
\hline 3 & 28 & $2400 \pm 20$ & 902.1 & 49.6 & $49.6 \pm 0.7$ \\
\hline 4 & 28 & $2390 \pm 30$ & 902.8 & 49.5 & $49.5 \pm 0.8$ \\
\hline 5 & 28 & $2400 \pm 10$ & 945.3 & 52.2 & $52.2 \pm 0.8$ \\
\hline 6 & 28 & $2390 \pm 10$ & 893.8 & 49.2 & $49.2 \pm 0.6$ \\
\hline 7 & 104 & $2390 \pm 10$ & 1015.9 & 56.6 & $56.6 \pm 0.8$ \\
\hline 8 & 104 & $2400 \pm 20$ & 921.1 & 51.7 & $51.7 \pm 0.7$ \\
\hline 9 & 104 & $2350 \pm 20$ & 952.9 & 52.7 & $52.7 \pm 0.7$ \\
\hline 10 & 104 & $2360 \pm 30$ & 1046 & 57.9 & $57.9 \pm 0.8$ \\
\hline 11 & 104 & $2370 \pm 10$ & 820.5 & 45.7 & $45.7 \pm 0.6$ \\
\hline \multirow[t]{2}{*}{12} & 104 & $2390 \pm 10$ & 1055.8 & 58.7 & $58.7 \pm 0.6$ \\
\hline & & & & \multicolumn{2}{|c|}{ Rounded to 0.1MPa + U } \\
\hline $\begin{array}{l}\text { Beam } 100 \times 100 \times 400 \mathrm{~mm} \\
\text { number }\end{array}$ & $\begin{array}{c}\text { Age } \\
\text { [day] }\end{array}$ & $\begin{array}{l}\text { Density } \\
{\left[\mathrm{kg} / \mathrm{m}^{3}\right]}\end{array}$ & $\begin{array}{c}\text { Failure load } \\
\mathbf{F}_{\max }[\mathbf{N}]\end{array}$ & $\begin{array}{c}\text { Compressive strength } \\
{[\mathrm{MPa}]}\end{array}$ & $\begin{array}{c}\text { Modulus of elasticity } \\
\text { [MPa] }\end{array}$ \\
\hline 1 & 28 & 2410.2 & 496062 & 49.61 & 35834 \\
\hline 2 & 28 & 2429.3 & 442777 & 44.28 & 37917 \\
\hline 3 & 28 & 2416.6 & 480298 & 48.03 & 38064 \\
\hline 4 & 104 & 2367.7 & 463782 & 46.38 & 35248 \\
\hline 5 & 104 & 2355.3 & 407064 & 40.71 & 35437 \\
\hline 6 & 104 & 2349.5 & 473738 & 47.37 & 32796 \\
\hline
\end{tabular}

Table 2: Cube compression tests, cylinder compression tests and three-point bending tests according to EN206 - $1^{20}$ for the small scale specimens of column C45/55

notch in a three-point bending configuration. Outcomes of such tests are not only basic mechanical parameters such as the modulus of elasticity, but also fracture parameters describing the behaviour of material during the fracture process and its crack propagation resistivity. Those parameters include effective crack elongation, effective fracture toughness, effective toughness and specific fracture energy. The volume density of the tested material can be also evaluated. In addition, compressive strength values can be obtained via 


\begin{tabular}{|c|c|c|c|c|c|}
\hline Cube $150 \times 150 \times 150 \mathrm{~mm}$ number & Age [day] & $\begin{array}{l}\text { Density } \\
{\left[\mathrm{kg} / \mathbf{m}^{3}\right]}\end{array}$ & \begin{tabular}{|c} 
Failure load \\
$F_{\max }[\mathbf{N}]$ \\
\end{tabular} & \multicolumn{2}{|c|}{ Compressive strength [MPa] } \\
\hline 1 & 28 & $2420 \pm 10$ & 2238.0 & 97.9 & $97.9 \pm 1.2$ \\
\hline 2 & 28 & $2410 \pm 10$ & 2233.0 & 98.3 & $98.3 \pm 1.2$ \\
\hline 3 & 28 & $2420 \pm 10$ & 2229.1 & 98.6 & $98.6 \pm 1.2$ \\
\hline 4 & 28 & $2420 \pm 10$ & 2136.0 & 94.5 & $94.5 \pm 1.1$ \\
\hline 5 & 28 & $2410 \pm 10$ & 2085.8 & 92.1 & $92.1 \pm 1.1$ \\
\hline 6 & 28 & $2410 \pm 10$ & 2139.3 & 93.9 & $93.9 \pm 1.1$ \\
\hline 7 & 116 & $2400 \pm 10$ & 2366.0 & 104.4 & $104.4 \pm 1.2$ \\
\hline 8 & 116 & $2410 \pm 10$ & 2379.4 & 104.6 & $104.6 \pm 1.2$ \\
\hline 9 & 116 & $2410 \pm 10$ & 2431.2 & 107.1 & $107.1 \pm 1.3$ \\
\hline 10 & 116 & $2420 \pm 10$ & 2391.8 & 105.8 & $105.8 \pm 1.3$ \\
\hline 11 & 116 & $2400 \pm 10$ & 2442.0 & 108.1 & $108.1 \pm 1.3$ \\
\hline \multirow[t]{2}{*}{12} & 116 & $2410 \pm 10$ & 2461.0 & 108.1 & $108.1 \pm 1.3$ \\
\hline & & & & \multicolumn{2}{|c|}{ Rounded to 0.1MPa + U } \\
\hline Cylinder $\phi 150 \times 300 \mathrm{~mm}$ number & Age [day] & $\begin{array}{l}\text { Density } \\
{\left[\mathrm{kg} / \mathrm{m}^{3}\right]}\end{array}$ & $\begin{array}{c}\text { Failure load } \\
F_{\max }[\mathbf{N}]\end{array}$ & \multicolumn{2}{|c|}{ Compressive strength [MPa] } \\
\hline 1 & 28 & $2410 \pm 20$ & 1625.1 & 89.3 & $89.3 \pm 1.3$ \\
\hline 2 & 28 & $2420 \pm 20$ & 1367.9 & 75.3 & $75.3 \pm 1.1$ \\
\hline 3 & 28 & $2400 \pm 20$ & 1512.2 & 82.8 & $82.8 \pm 1.0$ \\
\hline 4 & 28 & $2390 \pm 30$ & 1692.2 & 93.2 & $93.2 \pm 1.1$ \\
\hline 5 & 28 & $2400 \pm 10$ & 1307.8 & 72.2 & $72.2 \pm 0.9$ \\
\hline 6 & 28 & $2390 \pm 10$ & 1647.5 & 91.5 & $91.5 \pm 1.8$ \\
\hline 7 & 117 & $2430 \pm 10$ & 1790.8 & 99.4 & $99.4 \pm 1.2$ \\
\hline 8 & 117 & $2460 \pm 30$ & 1251.5 & 70.4 & $70.4 \pm 1.2$ \\
\hline 9 & 117 & $2430 \pm 10$ & 1567.6 & 86.9 & $86.9 \pm 1.1$ \\
\hline 10 & 117 & $2450 \pm 10$ & 1639.3 & 85.9 & $85.9 \pm 1.1$ \\
\hline 11 & 117 & $2430 \pm 10$ & 1579.1 & 87.7 & $87.7 \pm 1.1$ \\
\hline \multirow[t]{2}{*}{12} & 117 & $2450 \pm 20$ & 1591.5 & 89.0 & $89.0 \pm 1.3$ \\
\hline & & & & \multicolumn{2}{|c|}{ Rounded to 0.1MPa + U } \\
\hline Beam $100 \times 100 \times 400 \mathrm{~mm}$ number & Age [day] & $\begin{array}{l}\text { Density } \\
{\left[\mathbf{k g} / \mathbf{m}^{3}\right]}\end{array}$ & \begin{tabular}{|c|} 
Failure load \\
$\boldsymbol{F}_{\max }[\mathbf{N}]$ \\
\end{tabular} & Compressive strength [MPa] & Modulus of elasticity [MPa] \\
\hline 1 & 28 & 2420.8 & 729775 & 72.98 & 42009 \\
\hline 2 & 28 & 2408.8 & 729542 & 72.95 & 42309 \\
\hline 3 & 28 & 2425.3 & 707412 & 70.74 & 41148 \\
\hline 4 & 104 & 2392.1 & 491390 & 49.14 & 37185 \\
\hline 5 & 104 & 2385.2 & 526881 & 52.69 & 36396 \\
\hline 6 & 104 & 2392.7 & 501324 & 50.13 & 37714 \\
\hline
\end{tabular}

Table 3: Cube compression tests, cylinder compression tests and three-point bending tests according to EN206-1 ${ }^{20}$ for the small scale specimens of column C100/115

compression tests of broken parts of comparison between the compressive the specimens tested in bending. In strength of the code specified cubes particular, such tests enable the and prisms with a rectangular cross- section. Beam specimens prepared for the three-point bending tests had original dimensions $100 \mathrm{~mm} / 100 \mathrm{~mm} /$ 
$400 \mathrm{~mm}$ and were casted, cured and stored under conditions identical to those used for the compression tests. The loading span of each beam was $380 \mathrm{~mm}$. The specimen had a central edge notch with a depth of about $35 \mathrm{~mm}$ (1/3 of the height of the specimen). The loading of specimens was applied continuously with a constant increment of displacement (about $0.1 \mathrm{~mm} / \mathrm{min}$ ) in the centre of the span. The result of the measurement is a load vs. mid-span deflection diagram (1-d diagram). It includes both prepeak and post-peak branches. The results of these comprehensive compression testing campaigns are presented in Tables 2 and 3 and were provided to the modelling expert group after their first simulation results, see the section Three-Point Bending Fracture Test.

\section{Round-Robin NL-FEM Modelling}

\section{IABSE Commission 1; Task Group TG 1.4}

As mentioned previously, the IABSE WC1 group was invited to join the Round-Robin Tests after Bratislava University had already invited service providers in the field of non-linear finite element modelling to make a prediction of column stability failure. The tasks and questions for the IABSE WC1 group were formulated more comprehensively and it was also of high interest to put a special focus on the comparison of results from different approaches, not only Finite Element Methods but also analytical approaches, in order to reveal any discrepancies between modelling techniques.

The non-linear modelling comprises the scattering of material parameters, the variable deformation and deflection effects during the loading process and the non-linear material laws. Time-dependent changes in material properties and its spatial distribution were not objectives of these studies and were eliminated mainly by specific production and testing procedures of the columns. These aspects are of interest in one of the next research steps.

The IABSE WC1 group motivation for participating in the Round-Robin Tests included the following:

- Non-linear numerical modelling is increasingly attracting interest in everyday engineering. In fact, the method is very powerful for the replication of the real structural behaviour and also for using material efficiently in the structure.

- Non-linear numerical modelling is more demanding for the users due to the requirements in: (a) a much more extensive characterization of the input quantities of the material constitutive laws, (b) a more complex structure discretization (to divide the structure in more parts in order to better describe the mechanical performance of the structure) with respect to classical methods, (c) the appropriate selection of the finite element types, (d) choosing the appropriate solution procedure, (e) a more complex interpretation of the simulation results and (f) the possible iterative adaptation for an optimized finite element model and results.

- Traditional deterministic methods are not sufficient to properly design and assess new and existing general or advanced engineering structures and their components which are subjected to a variety of complex loading conditions from natural and artificial environments. Due to uncertainties in loading conditions, material behaviour, geometric configurations and boundary conditions, the stochastic analyses techniques (which account for all of these uncertain aspects) must be applied to provide rational reliability analyses and to describe realistically the existing behaviour of engineering structures. Therefore, stochastic analyses techniques and their proper application for engineering structures requires a training programme that is portable, provides global acknowledgment, improves structural performance and sets benchmarks within the industry.

- The necessity for code-based and general safety formats for nonlinear finite element analyses techniques as well as the handling of the model and modelling uncertainties.

\section{Round-Robin Modelling Process Steps}

In the IABSE Commission 1 Task Group (TG1.4) meetings, the following analyses and modelling process steps exclusively relating to non-linear modelling and based on the experimental designs of the Slovak University of Technology in Bratislava were discussed and mutually agreed upon. However, with respect to the amount of accessible information for nonlinear modelling, the preliminary interests were (a) to elaborate on the scatter in the non-linear finite element predictions of the column stability failures that had been conducted by a smaller group from the Slovak University of Technology in Bratislava (STUBA) prior to the IABSE TG1.4 group participation in the round-robin simulations, and (b) to investigate and predict the column test results for concrete $C 45 / 55$ and $C 100 / 115$ as presented in Table 1 for C45/55. For the Round-Robin modelling procedure, there was an agreement on the following process steps in the context of the amount of accessible information for non-linear modelling.

- $\mathbf{1}^{\text {st }}$ Round-Robin modelling process step: Deterministic analyses based on the drawings without conformity test results - only drawings of the column with embedded reinforcement and point of axial load input (static sketch) were available. Participants were asked to analyse two piers - one made of concrete $\mathrm{C} 45$ / 55 and the other of concrete $\mathrm{C} 100 /$ 115 in accordance with available codes and standards.

- $2^{\text {nd }}$ Round-Robin modelling process step: Deterministic analyses based on the drawings with conformity test results - results of concrete samples were provided both for concrete C45/55 and C100/115. Results were based on the testing of 3 blocks 100/100/400 mm (104 days), 6 cubes $150 / 150 / 150 \mathrm{~mm}$ (103 days) and 6 cylinders $\varnothing 150 / 300 \mathrm{~mm}$ (104 days). The results comprised of age, density, failure load and compressive strength of specimens, as well as modulus of elasticity for block specimens.

- $3^{\text {rd }}$ Round-Robin modelling process step: Analyses based on the drawings with defined input parameters - the partners received input data (already prepared for the probabilistic analyses) in the form of probabilistic resistance models for concrete grades $\mathrm{C} 45 / 55$ and $\mathrm{C} 100 / 115$ in order to have the possibility to characterize the modelling uncertainties. Some of the partners included in this $3^{\text {rd }}$ Round-Robin not the information about the conformity test results. 
- $4^{\text {th }}$ Round-Robin modelling process step: Deterministic analyses based on the drawings with conformity test results and the test results of the column -partners were provided with experimental test results of the column specimen to update their models or to comment on their compliance with the experimental results.

- $5^{\text {th }}$ Round-Robin modelling process step: Probabilistic analyses based on the drawings with conformity test results and the test results of the column - no additional input was provided. The goal of this round was to focus on correlation effects and spatial variability. The goal of this round was to focus on correlation effects and spatial variability. A comprehensive probabilistic analysis is not the subject of this article due to the page limitation, which is dealt with in a subsequent article.

\section{Round-Robin Modelling Experts}

The experts in this study are wellregarded professionals in the fields of deterministic and probabilistic Nonlinear Finite Element and Discrete Element modelling techniques for structural concrete systems. Correspondingly, the performance predictions involved at least one substantive and one normative expert. The use of different expert characteristics aimed to reduce bias in the estimation outcomes. The experts in the specific study were drawn from the IABSE WC1 group and they include researchers, engineers and senior scientists. As a minimum, they have 3 years of professional experience in Non-linear Finite Element modelling and probabilistic modelling and they have completed the training programmes for non-linear simulation techniques. The following expert groups participated in the Round-Robin modelling process:

- STUBA: Vladimir Benko, Slovak University of Technology in Bratislava, Department of Concrete Structures and Bridges.

- BOKU: Alfred Strauss; University of Natural Resources and Life Sciences Vienna, Institute of Structural Engineering.

- UNIZG-FCE: Ana Mandić Ivanković, Mladen Srbić and Dominik Skokandić; University of Zagreb Faculty of Civil Engineering, Department of Structural Engineering.
- U-MINHO: José Matos, Neryvaldo Galvão; University of Minho, Institute for Sustainability and Innovation in Structural Engineering (ISISE).

- IFSTTAR: Pierre Marchand, André Orcesi, Mohammad El Hajj Diab, IFSTTAR - The French institute of science and technlogy for transport development and networks.

- CDL:Roman Wan-Wendner; Ghent University, Belgium and Krešimir Ninčević; Christian Doppler Laboratory, University of Natural Resources and Life Sciences Vienna, Austria.

\section{Round-Robin Modelling Posed Data and Questions}

For each of the expert groups, the different levels of information as described in the section Round-Robin Modelling Process Steps $\left(1^{\text {st }}\right.$ to $5^{\text {th }}$ round-robin modelling) were prepared and made available in chronological order after each completed round. The information of Figs. 2 and 3 were available as basic data. The expert groups were asked to generate and provide the data for the preparation of the following diagrams (see Figs. 10-16) of the columns made of C45/55 and C100/115 on the basis of the prior knowledge of the original modelling group, see the section Initial Capacity Prediction

- diagram presenting the normal force $N$ vs. Moment $M$ curves

- diagram presenting the normal force $N$ vs. strain $\varepsilon_{c}$ curves

- diagram presenting the normal force $N$ vs. displacement $e_{2}$ curves.

The data were merged into the diagrams shown in the section Task group TG 1.4 Experts predictions: 1st round - Deterministic analyses based on drawing information and thus provided a very good insight into the differently modelled system responses during the entire load cycle up to the stability failure and during the postpeak. The provided $N-M$ interaction and the $\mathrm{N}-e_{2}$ curves allowed a deeper insight into the system responses during the loading process and thus into the initiation or change of fracture processes, hence, the experts were also asked to characterize the maximum load capacity $N_{\max }$, the displacement $e_{2}$ at the $N_{\text {max }}$ load level and the associated bending moment $M_{\max }$ from their non-linear analyses. These values allow unambiguous comparability of the predictions with the experimentally obtained data shown in Table 1.

In order to gain a deeper insight into the causes of the deviations in the non-linear modelled column responses, each expert group was asked to produce a report on the modelling in accordance with the Guidelines for non-linear finite element analysis of concrete structures ${ }^{27}$ which summarized the input values, the constitutive laws used, the discretization strategy, the modelled constraints and the solution algorithms as well as other parameters.

This chosen procedure should make it possible to reconstruct the gradual adaptation of the non-linear model formations and the improvement in the predictions of the stability failure of the columns after each new roundrobin information level, see the section Round-Robin Modelling Process Steps, and to exclude human errors if possible. Furthermore, this procedure provides an insight into the advanced NLFEM settings, constitutive laws, solution algorithms, etc. as chosen by the experts.

\section{Modelling Strategy}

A thorough planning of a finite element analysis reduces the risks of errors and the required time and thus cuts costs. ${ }^{27}$ Furthermore, the results of a finite element analysis should be reported in a standard fashion in order to reduce the time and costs associated with reviewing and archiving the analysis. More information on performing and reporting the results of a finite element analysis can be found in Ref. [27]. According to Hendriks, ${ }^{27}$ the analysis report should contain at least: 1. Specifications; 2. Model Preparation and Checking; 3. Analysis; 4. Validation and 5. Post Analysis Checks, see Ref. [27] for more details. From the above-mentioned submitted reports, it could be seen that most of the partners implemented these recording steps in their analyses. In the following, one briefly summarizes the overall modelling strategies considered by the experts. In particular, all the partners agreed that non-linear finite element modelling was a suitable analysis type. Some expert groups processed the tasks by using finite element bar elements, some using finite element 


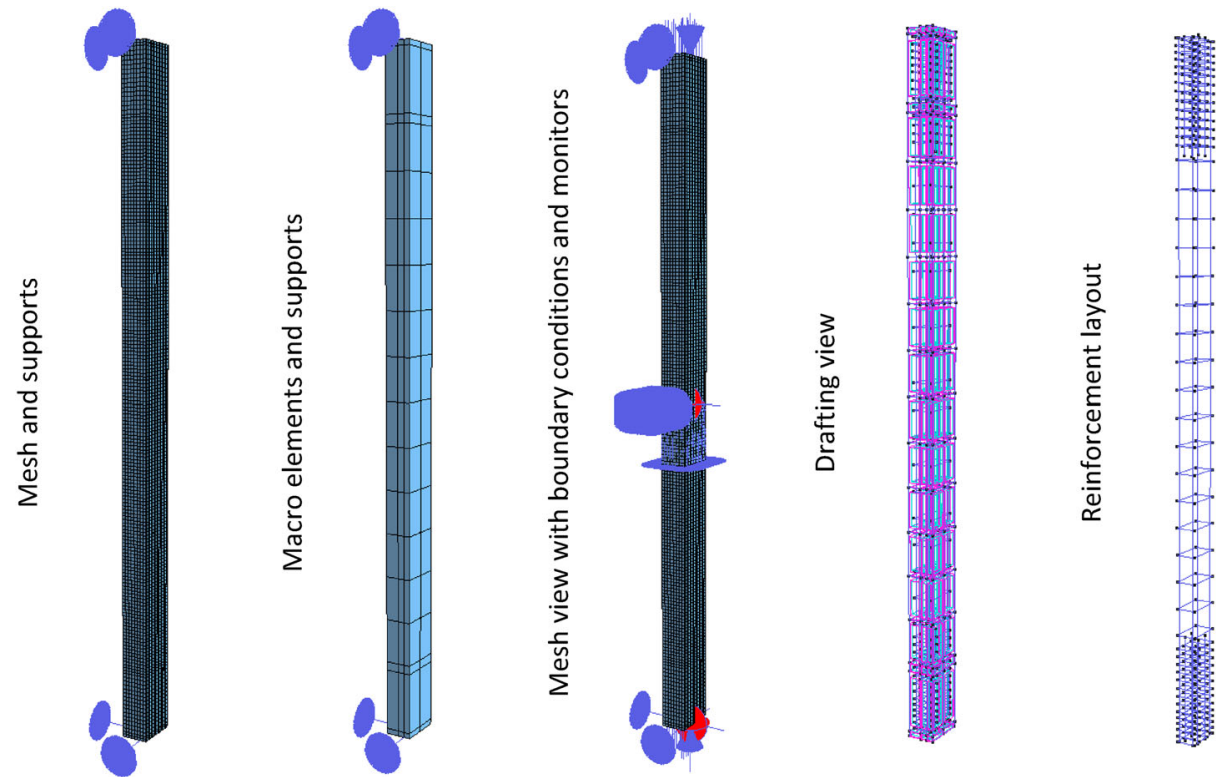

Fig. 6: Characteristics of the ATENA Scientific 3D Finite Element Model for the slender column C45/55 \& C100/115

beam elements and some using finite element solids. An analytical model was also considered as an alternative modelling strategy by one partner. The software packages used include ATENA 2D Release 2016, ATENA 3D Engineering Release 2018, ATENA 3D Science Release 2019, DIANA Release 2019, Sofistik, Fedeaslab as well as others.

BOKU provided e.g. the type, the number, and the integration scheme of elements, as well as the associated boundary conditions as presented in Fig. 6. In particular, Fig. 6 presents the elementation, macro zoning, boundary conditions and supports, as well as the reinforcement layout.

FCE-UNIZG provided the following details for modelling and, subsequently, for the examination of modelling:

- the beam type FE model with crosssections and embedded reinforcement was made according to the drawing provided at the beginning of the round-robin activity,

- Axial force acting in the point constraint (KF fix kinematic condition) with default eccentricity was set up as loading. Force is acting at the top support allowing vertical translation, while support at the bottom as for all translations is constrained,

- Beam type model of the pier $L=$ $380 \mathrm{~cm}$ long $(L)$ with different cross-sections comprising constant outer dimension $h \cdot b=150$. $240 \mathrm{~cm}$, but following changes in reinforcement are developed Length of beam elements $1 \mathrm{~cm}$,

- Longitudinal reinforcement is modelled as single reinforcement in $\mathrm{cm}^{2}$ $\left(A_{\mathrm{s}}\right)$ and shear reinforcement is modelled in shear cuts in $\mathrm{cm}^{2} / \mathrm{m}$ $\left(A_{\mathrm{ss}}\right)$ of the column length,

- Axis distances of reinforcement were set up as determined with drawings with $d_{1}=33 \mathrm{~cm}$,

- The same simple finite element model of the system was kept through all of the assignment rounds.

Concrete was modelled using set up stress-strain relation for non-linear structural analysis according to 3.1.5 in EN 1992-1-1:2004, with $f_{\text {cm }}$ e.g from FEM database, as shown in Fig. 7. FCEUNIZG used the concrete stress-strain relation for non-linear analysis according to EN 1992-1-1: 2004, as shown in Fig. 7. It is worth mentioning that the descending part of the stress-strain curve cannot be approached in this way with

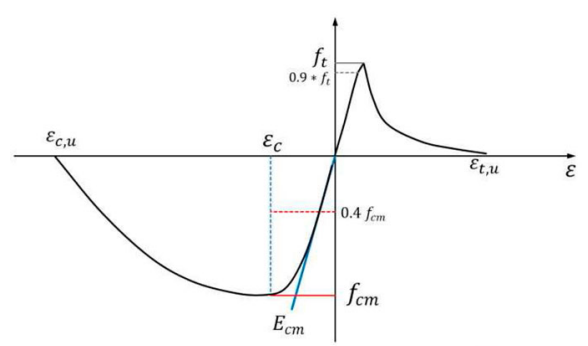

$\sigma_{c} / f_{c m}=\left(k \cdot \eta-\eta^{2}\right) /(1-(k-2) \cdot \eta) ; \eta=\varepsilon_{c} / \varepsilon_{c 1} ; \varepsilon_{c 1}$ is the strain at the peak stress; $k=1.05 \cdot E_{c m} \cdot\left|\varepsilon_{c 1}\right| / f_{c m}$

Fig. 7: Schematic representation of the concrete stress-strain relation for non-linear analysis according to EN 1992-1-1:2004 all of the available software (i.e. Sofistik). Namely, until the top point of the stressstrain curve, the Elastic Modulus is positive and monotone, but after the top point the stiffness would be negative, and therefore cannot be handled. The same approach with a controlled deformation analysis gave the same results. For the purpose of this assignment, in order to reveal the maximum axial force $N_{\max }$ load level and adequate bending moment $M_{N \max }$, the ascending part of the curve should be sufficient.

CDL group introduced a discrete constitutive concrete model developed in Refs. [28,29] and used it to perform the non-linear analyses (Fig. 8). The well-established Lattice-Discrete Particle Model (LDPM) simulates the behaviour of concrete at the meso-scale and reproduces largely its inherent material heterogeneity. The behaviour of the material is simulated by the mechanical interaction of coarse aggregate pieces embedded in a cementitious matrix. The assumed spherical aggregates were randomly placed in a predefined geometrical domain, following a Fuller sieve curve. After the aggregate placement, polyhedral cells were created by a three-dimensional tessellation following a Delaunay tetrahedralisation. Nodes with zero radius were generated on the external surfaces to define the concrete domain and to facilitate the load application and the boundary conditions. Finally, the material behaviour was described by a set of vectoral constitutive equations imposed on the facets of each neighbouring polyhedral cell. They directly captured the governing lower scale phenomena that are cohesive softening in tension, frictional shear under low confinement and hardening with pore collapse under high confinement. A more detailed description and model formulations can be found in Refs. [28,29].

The main relevant mechanical parameters of the damage model for this problem are normal modulus, tensile strength, tensile characteristic length and shear strength ratio. As these parameters represent the local mesoscale properties of cement paste attached to coarse aggregate pieces, they have to be inversely calibrated based on simulated standard tests. In this case, three different numerical models were used to calibrate the above-mentioned parameters. A unique set of parameters was chosen in order to capture all concrete short- 

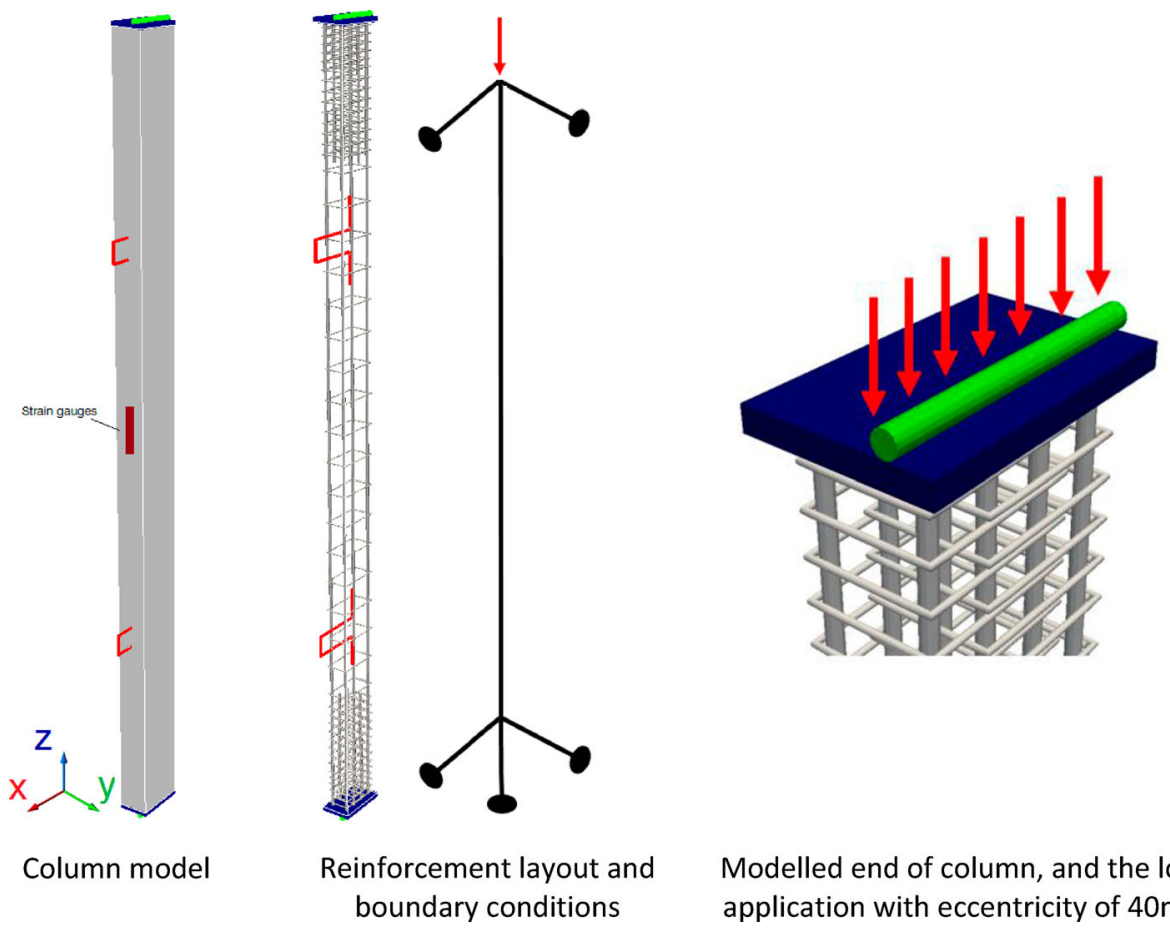

Fig. 8. Column model used in the LDPM analysis with some relevant details

term properties in order to simulate the concrete cube and cylinder compression tests and four-point bending tests (firstly for code suggested properties $=1^{\text {st }}$ round-robin modelling and secondly for experimentally obtained ones $=2^{\text {nd }}$ round-robin modelling).

The LDPM meso-scale concrete parameters were calibrated in order to represent concrete properties suggested by the codes for the C45/55 and C100/115 concrete strength classes. Based on the suggested code equations, calibrations were performed to obtain the concrete properties detailed in Table 4.

IFSTTAR considered two models. First, a finite element method, denoted IFSTTAR1, with nonlinear static analysis was applied using the MATLAB toolbox FEDEASLab, ${ }^{30}$ where the multilayer approach was used to model the column with corotational formulations to take into account the geometrical non-linearities. Second, an analytical model (denoted IFSTTAR2) was used as an alternative to a finite element modelling. In this model, one determines a $M-\chi$ (bending moment - curvature) relationship for different values of $N$ (axial load). To do so, different values of couple $\left(\varepsilon_{\text {inf }}, \varepsilon_{\text {sup }}\right)$ are considered, corresponding to the strain at lower and upper chord of the cross-section. For each couple the axial force $N$ and bending moment $M$ are determined

\begin{tabular}{|l|l|l|r|}
\hline $\mathbf{X}$ & \multicolumn{1}{|c|}{ Variable } & Unit & \multicolumn{1}{|c|}{$\mathbf{X}_{\mathbf{k}}$} \\
\hline \multicolumn{2}{|l|}{ Concrete C45/55 } & & \\
\hline$f_{c m}$ & Concrete compressive strength - mean & $\mathrm{MPa}$ & 53.0 \\
\hline$f_{c m, c u b e}$ & Concrete compressive strength cube - mean & $\mathrm{MPa}$ & 63.0 \\
\hline$f_{c t m, f l}$ & Concrete tensile strength & $\mathrm{MPa}$ & 6.3 \\
\hline$E_{c m}$ & Initial tangent concrete modulus of elasticity & $\mathrm{MPa}$ & 36280 \\
\hline Concrete & C100/115 & & \\
\hline$f_{c m}$ & Concrete compressive strength - mean & $\mathrm{MPa}$ & 108.0 \\
\hline$f_{c m, c u b e}$ & Concrete compressive strength cube - mean & $\mathrm{MPa}$ & 123.0 \\
\hline$f_{c t m, f l}$ & Concrete tensile strength & $\mathrm{MPa}$ & 8.7 \\
\hline$E_{c m}$ & Initial tangent concrete modulus of elasticity & $\mathrm{MPa}$ & 42880 \\
\hline
\end{tabular}

Table 4: Concrete resistance model derived for $1^{\text {st }}$ round of modelling

by integrating the concrete stress and force in the rebars. For each values of axial force $N_{i}$ considered, one determines the couples $\left(\varepsilon_{\text {inf }}, \varepsilon_{\text {sup }}\right)$ for which $N=N_{i}$ and the corresponding bending moments values. One can then deduce the corresponding curvature values $\chi$ to obtain a graph $M-\chi$ at $N=N_{i}$. Then, one integrates the curvature along the half height of the column (resolving an ordinary differential equation) with different eccentricity values at midheight, and one chooses the eccentricity at mid-height of the column leading to the adequate value of eccentricity at the top of the column. Gathering all the couples $N-e_{2}$ obtained according to the process described above, one obtains the global law $N$ function of $e_{2}$. This procedure takes into account the two cross-sections that co-exist in this column with cross-section 1 (4 longitudinal $14 \mathrm{~mm}$ diameter rebars at the middle of the column) and crosssection 2 (8 longitudinal $14 \mathrm{~mm}$ diameter rebars at the top and the bottom of the column). Besides, the model relies on the bilinear law described in clause 3.2.7 (2a) of EN1992-1-1 for steel rebars, the law for $\mathrm{C} 45 / 55$ as stipulated by EN 1992-1-1 and the fib Model Code $^{31}$ law for C100/115, as $100 \mathrm{MPa}$ is out of scope of EN 1992-1-1 (see Table 5).

\section{Task group TG 1.4 Experts predictions: $1^{\text {st }}$ round - Deterministic analyses based on drawing information}

As already outlined in the section Round-Robin Modelling Process Steps, the code information and the details of the design drawings were used as the basis for the modelling of the slender column elements by the 8 partners. Figures 9 and 10 present the NL-FEM system/column responses obtained from each partner in the "Normal-force-Moment $N-M$ ", the "Normal-force-Concrete Strain $N-\varepsilon_{\mathrm{c}}$ " and the "Normal-force-Horizontal Displacement $\mathrm{N}-e_{2}$ ". The following features can be read from these diagrams: (A) The "Normal-forceMoment $N$ - $M$ " diagram in the top/left of Fig. 9 shows a minimum value of $N_{\text {min, } N L F E M, C 45 / 55}=300 \mathrm{kN}$ and a maximum value $N_{\max , N L F E M, \mathrm{C} 45 / 55}=$ $400 \mathrm{kN}$ of the NL-FEM calculations for the column designed for concrete type $\mathrm{C} 45 / 55$. For the column designed for concrete type C100/115, the minimum value of $N_{\text {min,NLFEM,C100/ }}$ $115=380 \mathrm{kN}$ and the maximum value 


\begin{tabular}{|l|l|c|c|}
\hline $\mathbf{X}$ & \multicolumn{1}{|c|}{ Variable } & Unit & $\mathbf{X}_{\mathbf{k}}$ \\
\hline Concrete C45/55 & & \\
\hline$f_{c m}$ & Concrete compressive strength - mean & $\mathrm{MPa}$ & 53 \\
\hline$E_{c m}$ & Initial tangent concrete modulus of elasticity & $\mathrm{MPa}$ & 36300 \\
\hline Concrete C100/115 (according to fib Model Code) & & \\
\hline$f_{c m}$ & Concrete compressive strength - mean & $\mathrm{MPa}$ & 108 \\
\hline$E_{c i}$ & Tangent modulus of elasticity of concrete at a stress & & 47500 \\
\hline$E_{c 1}$ & Secant modulus from the origin to the peak compressive stress & $\mathrm{MPa}$ & 36000 \\
\hline$\varepsilon_{c, 1}$ & Concrete strain at maximum compressive stress & & $-3 \%$ \\
\hline$\varepsilon_{c, l i m}$ & Ultimate strain of concrete in compression & & $-3 \%$ \\
\hline
\end{tabular}

Table 5: Concrete resistance model derived for $1^{\text {st }}$ round of modelling

$N_{\text {max }, N L F E M, \mathrm{C} 100 / 115}=520 \mathrm{kN} \quad$ were obtained, see Fig. 10. The moments attributed to the above indicated normal forces are $M_{N \min / \mathrm{C} 45 / 55}=28$ $\mathrm{kNm}$ and $M_{N \max / \mathrm{C} 45 / 55}=32 \mathrm{kNm}$ for slender column elements designed for concrete C45/55 (see Fig. 9) and $M_{\text {Nmin } / \mathrm{C} 100 / 115}=34 \mathrm{kNm}$ and $M_{\text {Nmax }}$ $\mathrm{C} 100 / 115=40 \mathrm{kNm}$ for slender column elements designed for concrete C100/ 115 (see Fig. 10). These scatters in values include the blurring of the software specific algorithms as well as the blurring or errors generated in the
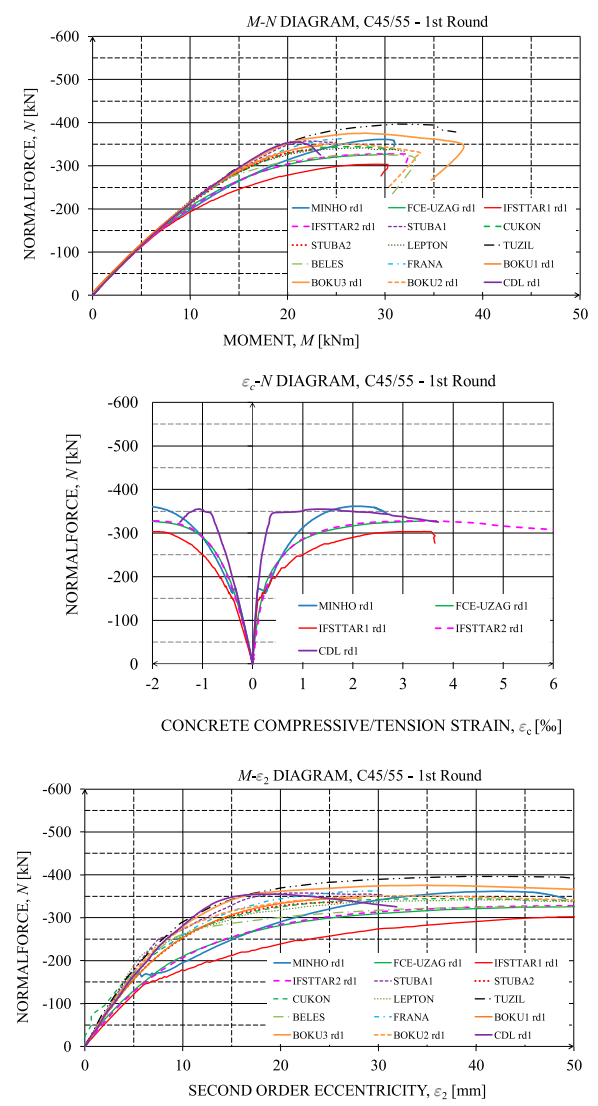

Fig. 9: Performance graphs of the slender column made of concrete C45/55 based on the code-based characteristics model input parameters by the users. (B) The "Normal-force-Concrete Strain $N-\varepsilon_{\mathrm{c}}$ " diagram in the top/right of Fig. 9 shows a clear transition from linear to non-linear performance and consequently to failure due to concrete crash in the compression zone. In all of haviour of the slender columns was evident after a normal force of approximately $N \cong 180 \mathrm{kN}$ for $\mathrm{C} 45 / 55$ and C100/115 (see Fig. 10). The concrete compression strain $e_{\mathrm{c}}$ for $\mathrm{C} 45 / 55$ (Fig. 9) and C100/115 (Fig. 10) was calculated at the bearing capacity by most
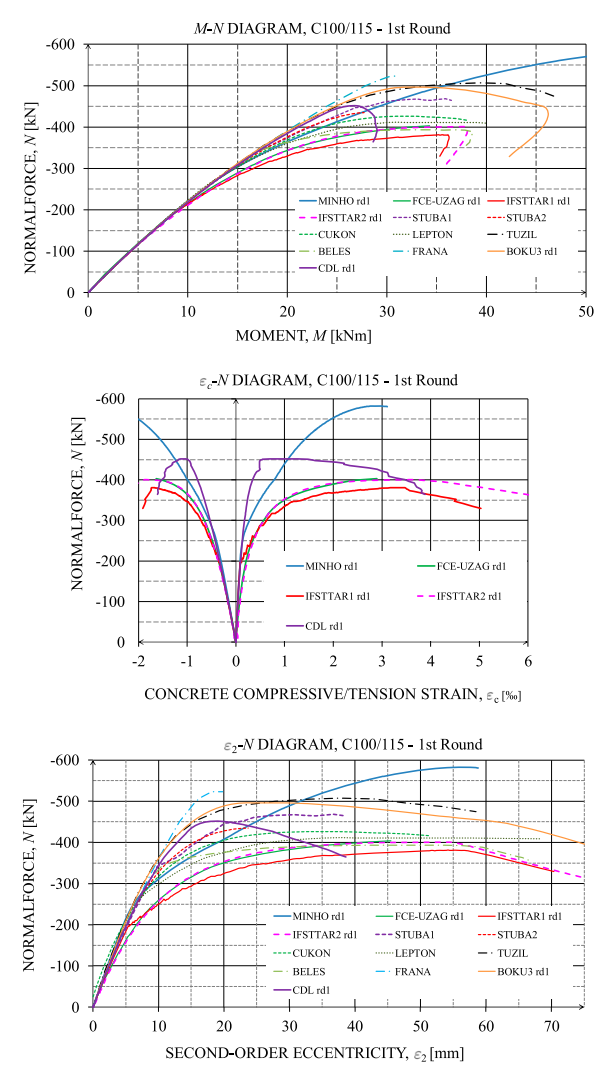

Fig. 10: Performance graphs of the slender column made of concrete C110/115 based on the code-based characteristics the partner's graphs, the non-linear be- of the partners with $e_{\mathrm{c}}=2 \%$ and the associated reinforcement tension strains in the tension zone of the column between $e_{\mathrm{s}}=2.8 \%$ o to $3.6 \%$ o (C) The "Normal-force-Horizontal Displacement $\mathrm{N}-e_{2}$ " diagram in the bottomleft of Fig. 9 shows a jump in the horizontal displacement $e_{2}$ for some of the partners calculations at approx. $N \cong$ $180 \mathrm{kN}$ for C45/55 and C100/115 (see also Fig. 10). The horizontal displacements attributed to the above indicated normal forces are $e_{2, \mathrm{Nmin} / \mathrm{C} 45 / 55}=45 \mathrm{~mm}$ and $e_{2, N \max / \mathrm{C} 45 / 55}=40 \mathrm{~mm}$ for concrete $\mathrm{C} 45 / 55$ (see Fig. 9) and $e_{2, \mathrm{Nmin} / \mathrm{C} 100 /}$ $115=55 \mathrm{~mm}$ and $e_{2, N \max / \mathrm{C} 100 / 115}=$ $40 \mathrm{~mm}$ for concrete C100/115 (see Fig. 10). (D) From these investigations the following statistical parameters can be determined: $N_{\mathrm{C} 45 / 55}=\mathrm{LN}(m=352 \mathrm{kN} ; v$ $=0.2) ; \quad M_{\mathrm{C} 45 / 55}=\mathrm{LN}(m=37 \mathrm{kNm} ; \quad v=$ $0.25) ; \quad e_{2}, \mathrm{C} 45 / 55=\mathrm{N}(m=42 \mathrm{~mm} ; \quad v=$ $0.18)$; respectively $N_{\mathrm{C} 100 / 115}=\mathrm{L} \mathrm{N}(m=$ $480 \mathrm{kN} ; v=0.18) ; M_{\mathrm{C} 100 / 115}=\mathrm{LN}(m=$ $36 \mathrm{kNm} ; \quad v=0.23) ; e_{2}, \mathrm{C} 100 / 115=\mathrm{N}(m=$ $48 \mathrm{~mm} ; v=0.20)$.

The $\mathbf{1}^{\text {st }}$ Round-Robin modelling process step which includes the Deterministic analyses of the invited expert groups using the information from design drawings, code information but not the information from conformity test results shows a scattering in the normal force for the $\mathrm{C} 45 / 55$ between $N_{\text {min, NLFEM,C45/55 }}=300 \mathrm{kN}$ and $N_{\text {max }}$, $N L F E M, \mathrm{C} 45 / 55=400 \mathrm{kN}$, which is associated with a model uncertainty of $\phi_{N L F E M, C 45 / 55}=1+50 / 350=1.14$ and with respect to the experimental data $\phi_{E X P, \mathrm{C} 45 / 55}=1+35 / 315=1.11$. For the C100/115 the scattering was between $N_{\text {min,NLFEM,C100/115 }}=380 \mathrm{kN}$ and $N_{\text {max }, N L F E M, \mathrm{C} 100 / 115}=580 \mathrm{kN}$, which is associated with a model uncertainty of $\phi_{N L F E M, C 100 / 115}=1+$ $100 / 480=1.20$ and with respect to the experimental data $\phi_{E X P, \mathrm{C} 100 / 115}=1+$ $100 / 430=1.23$.

\section{Task group TG 1.4 Experts predictions: 2 nd round- Deterministic analyses based on 1st round and specimen experiments (Tables 2 and 3)}

In the second round, the test results of the small specimens experiments (Cube pressure tests, cylinder compression tests and three-point bending tests according to EN206-1) were made available to the partners. The partners adjusted their modelling input parameters using these tests information and standardized as well as 


\begin{tabular}{|l|l|c|c|}
\hline $\mathbf{X}$ & \multicolumn{1}{|c|}{ Variable } & Unit & $\mathbf{X}_{\mathbf{k}}$ \\
\hline Concrete C45/55 & & & \\
\hline$f_{c k, c u b e}$ & Concrete compressive strength - cubes & $\mathrm{MPa}$ & 73.83 \\
\hline$f_{c k, c y l}$ & Concrete compressive strength - cylinders & $\mathrm{MPa}$ & 53.88 \\
\hline$f_{c m}$ & Concrete compressive strength - mean & $\mathrm{MPa}$ & 61.88 \\
\hline$\varepsilon_{c 1}$ & Strain at max. compressive stress & $\%$ & 2.49 \\
\hline$\varepsilon_{c u 1}$ & Ultimate strain & $\%$ & 3.50 \\
\hline$E_{c m}$ & Initial tangent concrete modulus of elasticity & $\mathrm{MPa}$ & 34494 \\
\hline Concrete C100/115 & & & \\
\hline$f_{c k, c u b e}$ & Concrete compressive strength - cubes & $\mathrm{MPa}$ & 106.35 \\
\hline$f_{c k, c y l}$ & Concrete compressive strength - cylinders & $\mathrm{MPa}$ & 86.55 \\
\hline$f_{c m}$ & Concrete compressive strength - mean & $\mathrm{MPa}$ & 94.55 \\
\hline$\varepsilon_{c 1}$ & Strain at max. compressive stress & $\%$ & 2.80 \\
\hline$\varepsilon_{c u 1}$ & Ultimate strain & $\%$ & 2.80 \\
\hline$E_{c m}$ & Initial tangent concrete modulus of elasticity & $\mathrm{MPa}$ & 37098 \\
\hline
\end{tabular}

Table 6: Concrete resistance model derived by FCE-UNIZG for the 2 nd round of modelling

advanced updating procedures. This type of information also assisted in characterizing the time-dependence of the input parameters of the modelling, with the input parameters of the modelling established by most of the partners for the time of 108 days at the time of the support tests. As illustration, FCEUNIZG updated the concrete models of the $1^{\text {st }}$ round with the material tested data as shown in Table 6.

Although data for 28 and 103/116/117 days old concrete was provided, data for older concrete was used as suggested by the initiator of the round-robin activity. Concerning the LPDM analysis, in contrast to the $1^{\text {st }}$ round where the concrete calibration was based on code suggestions, in the $2^{\text {nd }}$ round the experimentally obtained values for concrete properties were considered. The LDPM meso-scale concrete parameters were calibrated based on the experimentally obtained values, as shown in Table 6 . Figures 11 and 12 present the NLFEM system/column responses obtained from each partner in the "Normal-force-Moment- $N-M$ ", the "Normal-force-Concrete Strain $N-\varepsilon_{\mathrm{c}}$ " and the "Normal-force-Horizontal Displacement $\mathrm{N}-\mathrm{e}_{2} "$.

\section{$2^{\text {nd }}$ round-Discussions with respect to $1^{\text {st }}$ round:}

The following conclusions can be drawn from these investigations: the variations in the normal forces as well as the moments were reduced in relation to the first round and the results approximate the experimental values. This applies to the columns of both concrete C45/55 and C100/C115.

The 2nd Round-Robin modelling process step which includes the deterministic analyses of the invited expert groups using the information from design drawings, code information and the information from small-scale conformity test results shows a scattering in the normal force for the C45/55 between $\quad N_{\min , N L F E M, C 45 / 55}=330 \mathrm{kN}$ and $N_{\max , N L F E M, C 45 / 55}=400 \mathrm{kN}$, which is associated with a model uncertainty of $\phi N_{L F E M, C 45 / 55}=1+35 / 365=1.10$ and with respect to the experimental data $\phi_{E X P, C 45 / 55}=1+50 / 315=1.15$. For the C100/115 the scattering was between $N_{\min , N L F E M, C 100 / 115}=370 \mathrm{kN}$ and $N_{\max }$, $N L F E M, \mathrm{C} 100 / 115=520 \mathrm{kN}$, which is associated with a model uncertainty of $\phi_{\text {NLFEM }, \mathrm{C} 100 / 115}=1+75 / 445=1.16$ and with respect to the experimental data $\phi_{E X P, \mathrm{C} 100 / 115}=1+15 / 430=1.03$.

\section{Task group TG 1.4 Experts predictions: $3^{\text {rd }}$ round - \\ Deterministic analyses for characterizing the modelling uncertainties}

In this process step, the modelling uncertainty was of primary interest. The material laws implemented in the finite element software codes and the
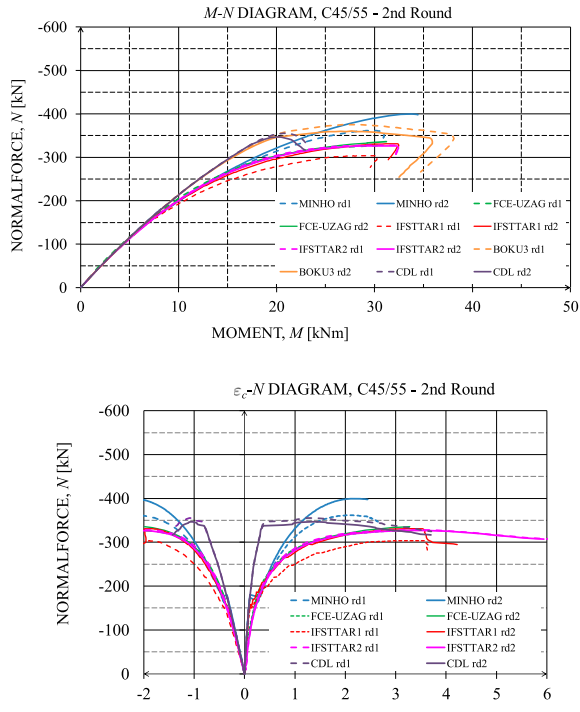

CONCRETE COMPRESSIVE/TENSION STRAIN, $\varepsilon_{\mathrm{c}}[\%]$

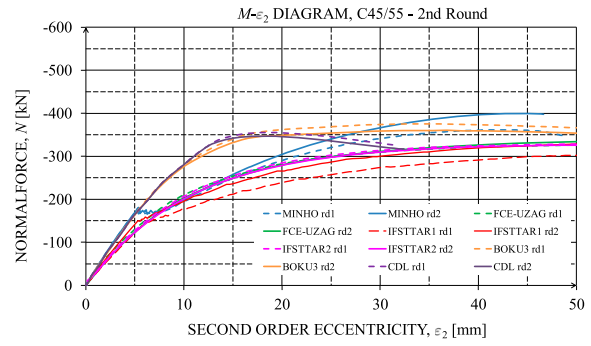

Fig. 11: Performance graphs of the slender column made of concrete C45/55 based on the small-scale specimen results (2nd round)
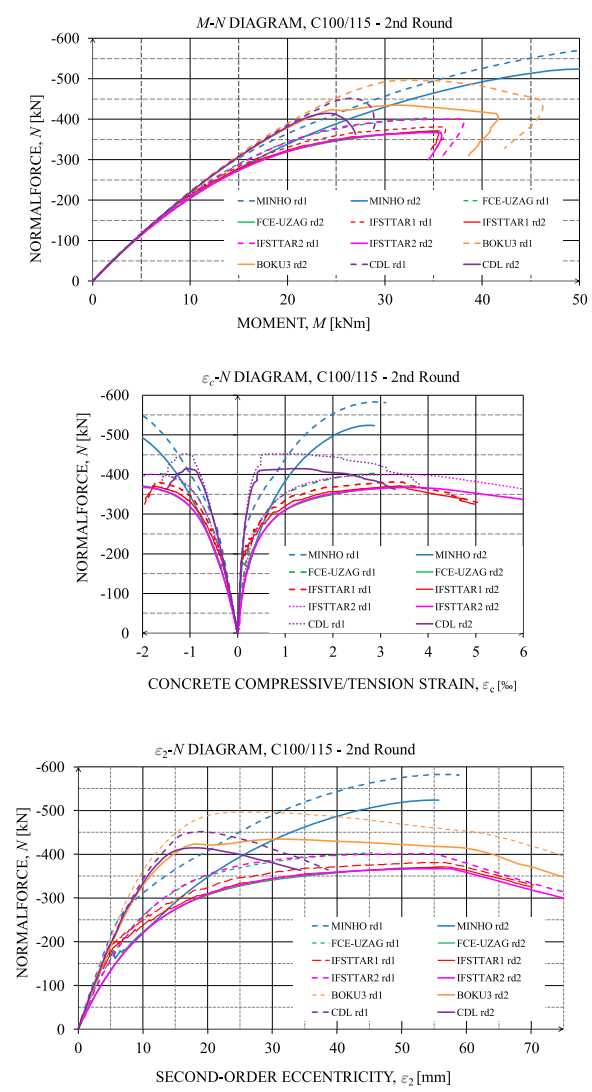

Fig. 12: Performance graphs of the slender column made of concrete C100/115 based on the small-scale specimen results (2nd round) 
solution algorithms were blurred, resulting in modelling uncertainties that were part of the model uncertainties. To determine this type of modelling uncertainty, the model input parameters for the partners participating in the Round-Robin Test were processed as shown in Table 7. By means of this preparation and the $2^{\text {nd }}$ round adaptation process, it was ensured that the scattering of the results only originates from the uncertainties in the material laws and software algorithm resolution. In general, a comprehensive processing of the model input parameters into nominal values, characteristic values, mean values and distribution types had been performed for the non-linear deterministic analyses.

Figures 13 and 14 present the NL-FEM system/column responses obtained from each partner in the "Normalforce-Moment $N$ - $M$ ", the "Normalforce-Concrete Strain $N-\varepsilon_{c}$ " and the
"Normal-force-Horizontal Displacement $N-e_{2} "$.

\section{$3^{\text {rd }}$ round - Findings regarding modelling uncertainties:}

The $\mathbf{3}^{\text {rd }}$ Round-Robin modelling process step which included the Deterministic analyses of the invited expert groups using the information from design drawings, code information and the information from the pre-defined input parameters for a probabilistic

\begin{tabular}{|c|c|c|c|c|c|c|c|}
\hline $\mathbf{X}$ & Variable & Dist. & & Unit & $\mathbf{X}_{k}$ & $\mu$ & $\sigma$ \\
\hline \multicolumn{8}{|c|}{$\mathrm{C} 45 / 55$} \\
\hline $\mathrm{X}_{1}$ & $f_{\mathrm{c}}$ & Concrete compressive strength & $\mathrm{LN}$ & $\mathrm{MPa}$ & 45.0 & 53.0 & 5.13 \\
\hline $\mathrm{X}_{2}$ & $f_{c t}$ & Concrete tensile strength & $\mathrm{LN}$ & $\mathrm{MPa}$ & 2.7 & 3.8 & 0.78 \\
\hline $\mathrm{X}_{3}$ & $G_{F}$ & Concrete fracture energy & $\mathrm{LN}$ & $\mathrm{MPa}$ & 104 & 149 & 30.8 \\
\hline $\mathrm{X}_{4}$ & $E_{c i}$ & Initial tangent concrete modulus of elasticity & $\mathrm{LN}$ & $\mathrm{GPa}$ & 37.5 & 37.5 & 4.91 \\
\hline $\mathrm{X}_{5}$ & $\varepsilon_{c, 1}$ & strain at max. compressive stress & $\mathrm{LN}$ & $\%$ & -2.50 & -2.50 & tbd. \\
\hline $\mathrm{X}_{6}$ & $\varepsilon_{c, l i m}$ & Ultimate strain & $\mathrm{LN}$ & $\%$ & -3.50 & -3.50 & tbd. \\
\hline $\mathrm{X}_{7}$ & $\varepsilon_{c t, \max }$ & Maximum tensile strain & $\mathrm{LN}$ & $\%$ & 0.15 & 0.15 & tbd. \\
\hline $\mathrm{X}_{8}$ & $k_{1}$ & Tension stiffening factor $\left(f_{c t}\right)$ & $\mathrm{LN}$ & & 0.6 & 0.6 & tbd. \\
\hline$X_{9}$ & $k_{2}$ & Tension stiffening factor $\left(\varepsilon_{c t, \max }\right)$ & $\mathrm{LN}$ & & 5.0 & 5.0 & tbd. \\
\hline $\mathrm{X}_{10}$ & $f_{y}$ & Reinforcing steel yield strength & $\mathrm{LN}$ & $\mathrm{MPa}$ & 500 & 548 & 40.0 \\
\hline $\mathrm{X}_{11}$ & $E_{\mathrm{s}}$ & Reinforcing steel modulus of elasticity & Det. & $\mathrm{GPa}$ & 200 & 200 & - \\
\hline $\mathrm{X}_{12}$ & $k$ & Ratio $\left(f_{t} / f_{\mathrm{y}}\right)_{k}$ for ductility class B & Det. & $\%$ & 1.08 & 1.08 & - \\
\hline $\mathrm{X}_{13}$ & $\varepsilon_{u}$ & Strain at max. tensile stress & Det. & $\%$ & 50 & 50 & - \\
\hline$X_{14}$ & $b$ & Width & $\mathrm{N}$ & $\mathrm{cm}$ & 24.0 & 24.0 & 0.90 \\
\hline$X_{15}$ & $h$ & Height & $\mathrm{N}$ & $\mathrm{cm}$ & 15.0 & 15.0 & 0.30 \\
\hline $\mathrm{X}_{16}$ & $A_{s 1}$ & Reinforcement area & $\mathrm{N}$ & $\mathrm{cm}^{2}$ & 3.08 & 3.08 & 0.062 \\
\hline $\mathrm{X}_{17}$ & $A_{s 2}$ & Reinforcement area & $\mathrm{N}$ & $\mathrm{cm}^{2}$ & 3.08 & 3.08 & 0.062 \\
\hline $\mathrm{X}_{18}$ & $d_{1}$ & Axis distance of reinforcement & $\mathrm{B}$ & $\mathrm{cm}$ & 3.30 & 3.30 & $0.66^{*}$ \\
\hline $\mathbf{X}_{19}$ & $d_{2}$ & Axis distance of reinforcement & $\mathrm{B}$ & $\mathrm{cm}$ & 3.30 & 3.30 & $0.66^{*}$ \\
\hline$X_{20}$ & $L$ & Length & Det. & $\mathrm{m}$ & 1.92 & - & - \\
\hline$X_{21}$ & $e_{0}$ & Eccentricity & $\mathrm{N}$ & $\mathrm{cm}$ & 4.00 & 4.00 & tbd. \\
\hline$X_{22}$ & $\theta_{R}$ & Resistance model uncertainty & $\mathrm{LN}$ & - & 1.00 & 1.00 & tbd. \\
\hline \multicolumn{8}{|c|}{$\mathrm{C} 100 / 115$} \\
\hline $\mathrm{X}_{1}$ & $f_{\mathrm{c}}$ & Concrete compressive strength & $\mathrm{LN}$ & $\mathrm{MPa}$ & 100.0 & 108.0 & 4.99 \\
\hline$X_{2}$ & $f_{c t}$ & Concrete tensile strength & $\mathrm{LN}$ & $\mathrm{MPa}$ & 3.7 & 5.2 & 1.08 \\
\hline$X_{3}$ & $G_{F}$ & Concrete fracture energy & $\mathrm{LN}$ & $\mathrm{MPa}$ & 119 & 170 & 35.0 \\
\hline $\mathrm{X}_{4}$ & $E_{c i}$ & Initial tangent concrete modulus of elasticity & $\mathrm{LN}$ & $\mathrm{GPa}$ & 48.9 & 48.9 & 6.23 \\
\hline $\mathrm{X}_{5}$ & $\varepsilon_{c, 1}$ & Strain at max. compressive stress & $\mathrm{LN}$ & $\%$ & -3.0 & -3.0 & tbd. \\
\hline$X_{6}$ & $\varepsilon_{c, \lim }$ & Ultimate strain & $\mathrm{LN}$ & $\%$ & -3.0 & -3.0 & tbd. \\
\hline
\end{tabular}

Notes: $\mathrm{a}, \mathrm{b}=\mu \pm 3 \sigma$.

Table 7: Model input parameters used for characterizing modelling uncertainties 

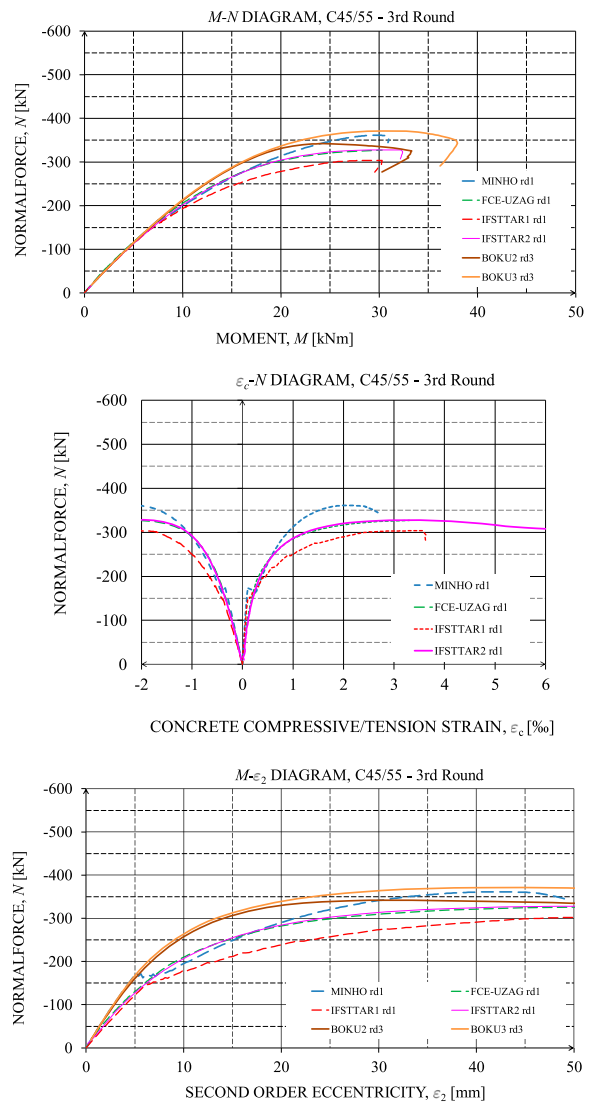

Fig. 13: Performance graphs of the slender column made of concrete C45/55 based on parameters for the determination of the modelling uncertainties ( $3^{\text {rd }}$ round)
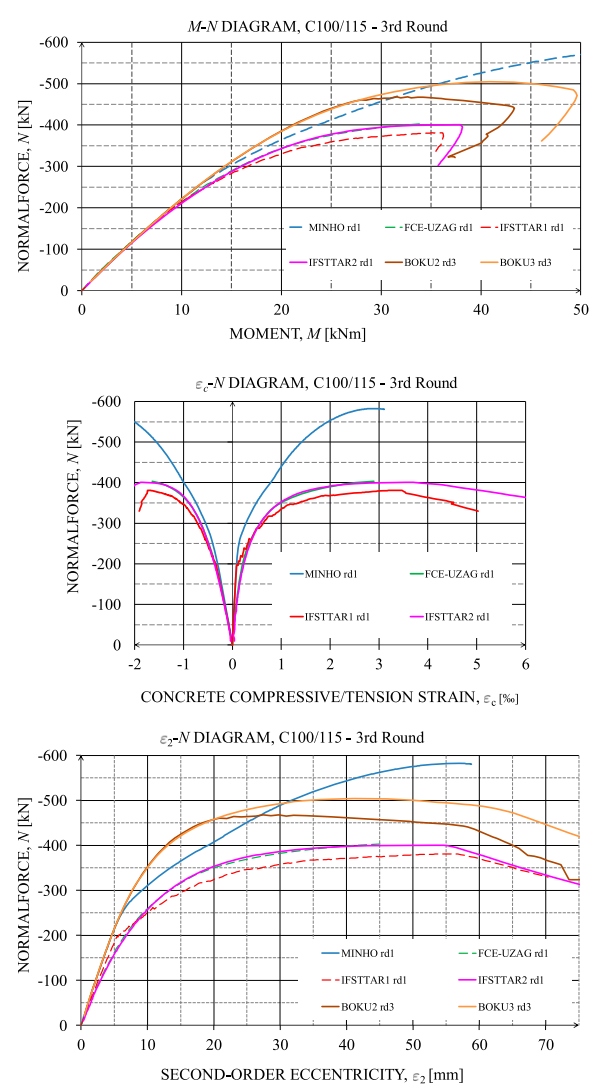

Fig. 14: Performance graphs of the slender column made of concrete C110/115 based on parameters for the determination of the modelling uncertainties ( $3^{\text {rd }}$ round) analysis showed a scattering in the normal force for the C45/55 between $N_{\text {min, NLFEM,C45/55 }}=300 \mathrm{kN}$ and $N_{\text {max }}$, $N L F E M, C 45 / 55=365 \mathrm{kN}$, which is associated with a model uncertainty of $\phi_{N L F E M, C 45 / 55}=1+32.5 / 332.5=1.10$ and with respect to the experimental data $\phi_{E X P, C 45 / 55}=1+17.5 / 315=1.06$. For the $\mathrm{C} 100 / 115$ the scattering was between $N_{\text {min, NLFEM,C100/115 }}=380 \mathrm{kN}$ and $\quad N_{\text {max }, N L F E M, C 100 / 115}=505 \mathrm{kN}$, which is associated with a model uncertainty of $\phi_{N L F E M, C 100 / 115}=62.5 / 443=$ 1.14 and with respect to the experimental data $\phi_{E X P, \mathrm{C} 100 / 115}=13 / 430=1.03$.

\section{Task group TG 1.4 Experts predictions: $4^{\text {th }}$ round -}

\section{Deterministic analyses based on $1^{\text {st }}$ \& $2^{\text {nd }}$ rounds and column tests}

After the production of experimental samples and preparation of laboratory conditions, the concrete columns were tested in The Central laboratory of the Civil Engineering faculty SUT Bratislava. During the experiment, measurements were taken on both sides of the concrete cross-section Despite the fact that columns were fabricated using the same materials and great care was taken for accuracy, the differences in results are notable. The major difference in buckling force reaches $15.9 \%$, whereas in deformations of columns in the middle $\left(e_{2}\right)$ it goes up to $44.9 \%$. The measurements were taken on 6 testing samples of slender concrete columns.

In this $4^{\text {th }}$ round (Figs. 15 and 16), model results from the $2^{\text {nd }}$ round and experimental results of the column tests were to be compared and reasons for deviations were to be investigated and elaborated upon. As illustration, the main idea of FCE-UZAG regarding the updating process was to adjust the assumed loading points of the out-of-centre forces and to adjust the geometrical sizes including the initial deformations in the testing device of the columns on the basis of the mean values obtained from previously calculated column test results. This procedure was to be applied for columns C45/55 and C100/115. However, the group compared results and concluded that their results were in good compliance with the experimental tests. Hence, the group did not go further with updating the model. Finally, the features of diagrams for the four rounds are summarized in Table 8.
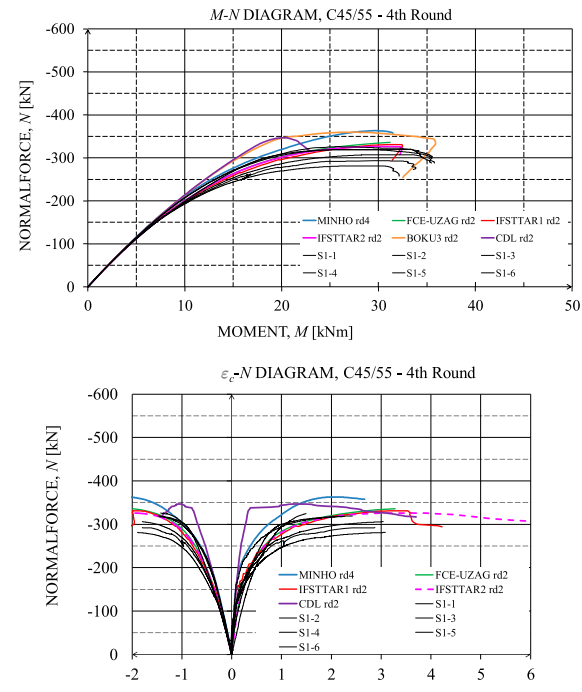

CONCRETE COMPRESSIVE/TENSION STRAIN, $\varepsilon_{\mathrm{c}}[\%]$

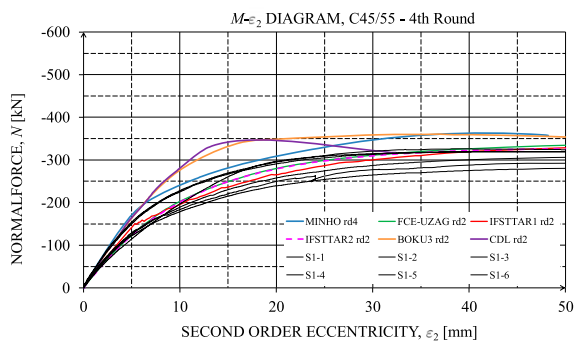

Fig. 15: Performance graphs of the slender column made of concrete C45/55 based on the information about the column experiments $\left(4^{\text {th }}\right.$ round)
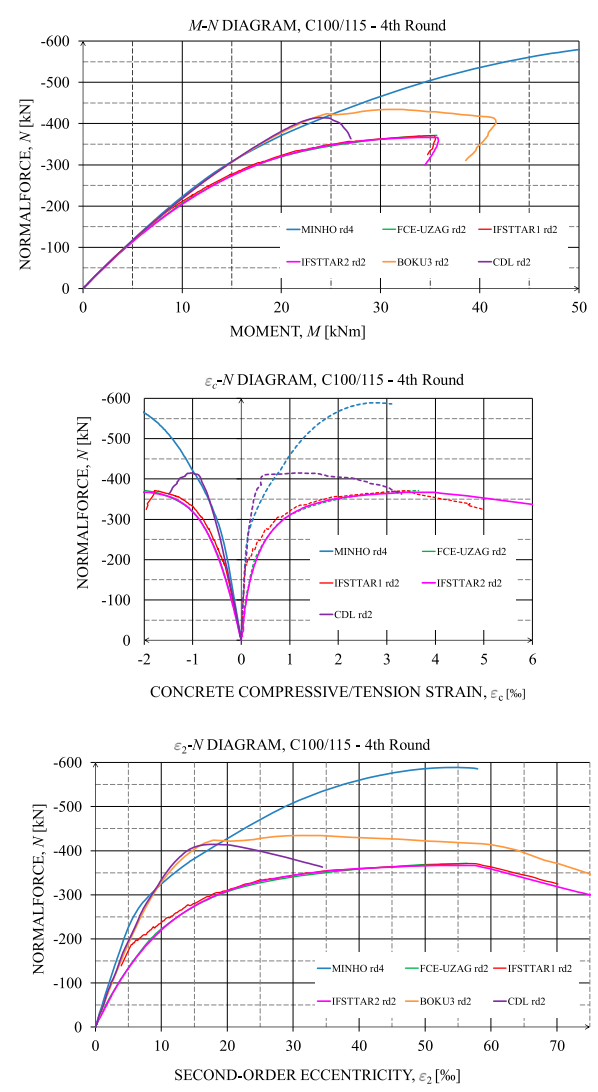

Fig. 16: Performance graphs of the slender column made of concrete C110/115 based on the information about the column experiments ( $4^{\text {th }}$ round) 


\begin{tabular}{|c|c|c|c|c|c|c|}
\hline Variable & Unit & $\begin{array}{c}\mathbf{1}^{\text {st }} \\
\text { Round }\end{array}$ & $\begin{array}{l}\text { 2nd } \\
\text { Round }\end{array}$ & $\begin{array}{c}\text { 3rd } \\
\text { Round* }\end{array}$ & $\begin{array}{c}\text { 4th } \\
\text { Round }\end{array}$ & Experiment \\
\hline \multicolumn{7}{|l|}{$\mathrm{C} 45 / 55$} \\
\hline$N_{\min , N L F E M, \mathrm{C} 45 / 55}$ & $\mathrm{kN}$ & 300 & 330 & 300 & 330 & 270 \\
\hline $\begin{array}{l}N_{\max , N L F E M, \mathrm{C} 45 /} \\
55\end{array}$ & $\mathrm{kN}$ & 400 & 400 & 365 & 355 & 360 \\
\hline$N_{N L F E M, \mathrm{C} 45 / 55}$ & $\mathrm{kN}$ & 100 & 70 & 65 & 25 & 90 \\
\hline$M_{N \min / \mathrm{C} 45 / 55}$ & $\mathrm{kNm}$ & 28 & 32 & 30 & 32 & 29 \\
\hline$M_{N \max / \mathrm{C} 45 / 55}$ & $\mathrm{kNm}$ & 32 & 34 & 31 & 30 & 27 \\
\hline$M_{N / \mathrm{C} 45 / 55}$ & $\mathrm{kNm}$ & 4 & 2 & 1 & 2 & 2 \\
\hline$e_{\mathrm{c}}$ & $\%$ & 2 & $1-2$ & 2 & $1-2$ & $1.5-1.9$ \\
\hline$e_{\mathrm{t}}$ & $\%$ & $2.8-3.6$ & $2.5-3.7$ & $2.8-3.6$ & $2.5-3.7$ & $1.5-3.2$ \\
\hline$e_{2, \mathrm{Nmin} / \mathrm{C} 45 / 55}$ & $\mathrm{~mm}$ & 45 & 50 & 50 & 50 & 45 \\
\hline$e_{2, N \max / \mathrm{C} 45 / 55}$ & $\mathrm{~mm}$ & 40 & 47 & 40 & 42.5 & 35 \\
\hline$e_{2, N / C 45 / 55}$ & $\mathrm{~mm}$ & 5 & 3 & 10 & 7.5 & 10 \\
\hline \multicolumn{7}{|l|}{$\mathrm{C} 100 / 115$} \\
\hline $\begin{array}{l}N_{\min , N L F E M, \mathrm{C} 100 /} \\
115\end{array}$ & $\mathrm{kN}$ & 380 & 370 & 380 & 370 & \\
\hline $\begin{array}{l}N_{\max , N L F E M, \mathrm{C} 100 /} \\
115\end{array}$ & $\mathrm{kN}$ & 580 & 520 & 505 & 440 & \\
\hline$N_{N L F E M, \mathrm{C} 100 / 115}$ & $\mathrm{kN}$ & 200 & 150 & 125 & 70 & \\
\hline$M_{N \min / \mathrm{C} 100 / 115}$ & $\mathrm{kNm}$ & 36 & 36 & 35 & 36 & \\
\hline$M_{N \max / \mathrm{C} 100 / 115}$ & $\mathrm{kNm}$ & 52 & 49 & 42 & 32 & \\
\hline$M_{N / \mathrm{C} 100 / 115}$ & $\mathrm{kNm}$ & 16 & 13 & 7 & 4 & \\
\hline$e_{\mathrm{c}}$ & $\%$ & 2 & $1.7-2$ & $1.7-2$ & $1.2-1.8$ & \\
\hline$e_{\mathrm{t}}$ & $\%$ & $2.8-3.6$ & $2.8-3.6$ & $2.8-3.5$ & $2.0-3.5$ & \\
\hline$e_{2, N \min / \mathrm{C} 100 / 115}$ & $\mathrm{~mm}$ & 56 & 57 & 56 & 56 & \\
\hline$e_{2, N \max / \mathrm{C} 100 / 115}$ & $\mathrm{~mm}$ & 55 & 55 & 43 & 35 & \\
\hline$e_{2, N / \mathrm{C} 100 / 115}$ & $\mathrm{~mm}$ & 1 & 2 & 13 & 21 & \\
\hline
\end{tabular}

benchmarking the expert numerical analysis results with the experimental results. Consequently, enhanced nonlinear FE analyses were carried out using small and large scale test results and the information from the partners. The main conclusions were:

- The initial structural NL-FEM of the columns (1st Round-Robin modelling process based on code information) indicated a higher normal force capacity than the tested columns and a high scattering of the results of the experts. It was shown that the modelled capacity had a significantly higher load-carrying capacity than the experiments.

- The enhanced structural NL-FEM of the columns (2nd Round-Robin modelling process), which was based on test information from laboratory small scale tests, revealed a remarkable improvement in the prediction of the load-carrying capacity with respect to the experimental results. The experts were not informed about the results of the experimentally tested columns. In addition, most of the NL-FEM analyses at this stage also revealed a failure mechanism where the column stability loss occurs far away from the Code defined N-M Interaction limit and the concrete compression strain in the high loaded cross-section at stability failure shows $2 \%$ at maximum, which is significantly lower than the $3.5 \%$ acceptable limit.

- A further enhanced structural NLFEM of the columns (4th RoundRobin modelling process) based on test information from the full-scale column tests, where the experts were informed about the results of the experimental tested columns, were no longer needed by most of the experts for the improvements of the predictions.

- the 1st Round-Robin modelling process (based on code information) and due to the scattering (model uncertainties) show from most of the partners an overestimation of the NL-FEM simulations with respect to the test results. Hence, it can be expected that there will be cases where the PSF method combined with NL-FEM leads to inaccurate un-safe prediction of the structural behaviour of slender column systems. Hence it is recommended that an additional system safety factor, which is not 
yet included in Eurocode, is included, in particular for NL-FEM analyses methods.

- Nonetheless, the bearing capacity of slender concrete column elements, such as computed by NL-FEM, is several times higher than the simplified code procedures, such as the nominal stiffness or nominal curvature method. Before such disparity, special training should be advised, and recommendations should be provided in the codes for NL-FEM analysis of slender columns in order the take full advantage of such methods for a more efficient, less conservative and accurate design procedure.

- In addition, it has been shown that the model uncertainty has an important influence on the safety verification and, thus, the prediction of the bearing capacity. Consequently, model uncertainty has to be taken into account properly, otherwise it can lead to an inaccurate structural assessment. Among the proposed safety concepts, it is only the improved $\mathrm{ECOV}^{27}$ and the full probabilistic method that account for the model uncertainty rationally.

- There is a lack of studies on the model uncertainty factor and its coefficient of variation for enhanced structural assessment using nonlinear FE analysis. Therefore, further studies are needed. A large number of decisions are required from the experts when dealing with non-linear FE analysis. As such, in order to reduce the analyst-dependent variability (modelling uncertainties) in the results and also the model uncertainties, guidelines for such analyses should be developed, examined and used.

This paper demonstrated that it is feasible to use NL- FEM analysis for the structural prediction of the bearing capacity of slender concrete columns. Such analyses are computationally more demanding than standard methods (nominal stiffness or nominal curvature method) and cognitively more demanding to the analysts, when it comes to the modelling and solution techniques, the use of information and the interpretation of NLFEM results. In order to reduce the risk of errors in capacity predictions, it is recommended that specific training and experience for formulation in codes are associated requirements for NL-FEM analysts. In addition, a discussion about a safety factor associated with NL-FEM applications should be initiated. Nevertheless, the studies of this paper demonstrate that NLFEM analysis can provide a tool to assess safety using realistic descriptions of material behaviour with actual material properties. In this way, a realistic estimation of the existing safety levels can be obtained utilizing "hidden" capacities by using "true" material properties.

\section{Acknowledgements}

The authors would like to acknowledge IABSE COM1 and the IABSE TG1.4 members for supporting this project.

\section{Funding}

This paper was partly carried out during research exchanges at TU Brno (BUT), Lehigh University (LU). The authors acknowledge also the financial support provided by the SAFEBRIDGE ATCZ190 EU Interreg project, the Scientific Grant Agency of the Ministry of Education of Slovak Republic, the Slovak Academy of Sciences VEGA No. 1/0696/14, and Slovak Research and Development Agency under the contract No. APVV-150658. The computational results presented have been achieved [in part] using the Vienna Scientific Cluster (VSC).

\section{ORCID}

Alfred Strauss (1) http://orcid.org/00000002-1674-7083

José Matos (1) http://orcid.org/00000002-1536-2149

Roman Wan-Wendner (1) http://orcid. org/0000-0003-3616-5694

\section{References}

[1] Suda J, Strauss A, Rudolf-Miklau F, Hubl J. Safety assessment of barrier structures. Struct. Infrastruct. Eng. 2009;5(4):311-324.

[2] Červenka V. Global safety format for non linear calculation of reinforced concrete. Beton und Stahlbetonbau 2008;103:37-42.

[3] Strauss A, Wendner R, Bergmeister K, Reiterer M, Horvatits J. Monitoring and influence lines based performance indicators [Modellkorrekturfaktoren als "performance Indi-katoren" für die Langzeitbewertung der integralen Marktwasserbrücke S33.24]. Betonund Stahlbetonbau. 2007;106(4):231-240.

[4] Benko V, et al. Failure of slender columns of loss of stability. In: Key Engineering Materials. Vol. 691, 2016; s. 185-194. ISSN 1013-9826.

[5] Strauss A, Vidovic A, Zambon I, Dengg F, Matos JC. Performance indicators for roadway bridges. Maintenance, Monitoring, Safety, Risk and Resilience of Bridges and Bridge Networks
Proceedings of the 8th International Conference on Bridge Maintenance, Safety and Management (IABMAS); 2016; 965-970.

[6] Benko V. et al. The reliability of slender concrete columns subjected to a loss of stabil-ity. In: Advances and Trends in Engineering Sciences and Technologies II: proceedings of the 2nd International Conference on Engineering Sciences and Technologies, High Tatras Mountains, Tatranské Matliare, Slovak Republic, 29 June-1 July 2016, London: Taylor \& Francis Group; 2017, S. 45-50. ISBN 978-1138-03224-8.

[7] Benko V, et al. Prediction of slender concrete columns resistance in case of stability failure. Beton TKS. Vol. 1; 2014.

[8] Strauss A, Benko V, Täubling B, Valašík A, Cuhák M. Zuverlässigkeit schlanker Betonstützen. Beton- und Stahlbetonbau. 2017;112(7):392-401.

[9] Benko V, Dobrý J, Čuhák M. Failure of slender concrete columns due to a loss of stability. Slovak J. Civil Eng. 2019;27:45-51.

[10] EN 1992-1-1. Eurocode 2: Design of concrete structures - Part 1-1. General rules and rules buildings; 2004.

[11] Benko V. Nichtlineare Berechnung von Stahlbetondruckglieder [Nonlinear analysis of reinforced concrete compression members]. In: Innovationen im Betonbau 27. Fortbild-ungsveranstaltung, OVBB Heft 47, 2001; s. 9-12.

[12] Moravčík M. et al. Experience with bridges of the older types of precast (Skúsenosti s mostami zo starších typov prefabrikátov). Betonárske dni, zborník prednášok, STU v Bratislave, 2012; s. 439-444. ISBN 978-80-8076-104-2.

[13] Pfeiffer U. Program: analysis of reinforced Concrete Structures, TUHH, Version 2.90; 2014.

[14] ÖNORM B 1992-1-1. Eurocode 2: Bemessung und Konstruktion von Stahlbetonund Spannbetontragwerken Teil 1-1: Grundlagen und Anwendungsregeln für den Hochbau; 2011.

[15] Benko V, Dobrý J, Čuhák M. slender concrete columns at the loss of stability. In: Better, Smarter, Stronger. Lausanne: Fédération internationale du beton (fib); 2018. ISBN 978-1-87704014-6.

[16] Podrucek J, Benko V, Kendicky P, Strauss A. Reliability assessment of concrete columns. The international conference on bridge maintenance, safety and management, Foz do Iguacu; Dec 5-7; 2016.

[17] Červenka V, Jendele L, Červenka J. ATENA Program Documentation - Part 1: theory. Cervenka Consulting. Prague; 2007.

[18] Novák D, Vořechovský M, Teplý B. FReET: software for the statistical and reliability analysis of engineering problems and FReET-D: degradation module. Adv. Eng. Softw. 2014;7:179-192.

[19] Iman R. C.; Conover W. J. Small sample sensitivity analysis techniques for computer models, with an application to risk assessment. Commun. Stat. Theory Methods. 1980;A9:1749-1842.

[20] EN-206-1. Concrete - Part 1: Specification, performance, production and conformity; 2005. 
[21] Zimmermann T, Lehký D, Strauss A. Correlation among selected fracture-mechanical parameters of concrete obtained from experiments and inverse analyses. Struct. Concrete 2016;17(6):1094-1103.

[22] Ang A-S, Tang W. Probability Concepts in Engineering Planning. 2nd ed. John Wiley \& Sons, Inc: Hoboken, NJ; 2007.

[23] ÖNORM-B-4710-1. Concrete - Part 1: specification, production, use and verification of conformity (rules for the implementation of ÖNORM EN 206-1); 2002.

[24] EN-12390-3. Testing hardened concrete - Part 3: Compressive strength of test specimens; 2009.
[25] EN-14651. Test method for metallic fibered concrete - measuring the flexural tensile strength (limit of proportionality (lop), residual); 2005.

[26] ÖNORM-B-3592. Determination of cutthrough-tensile splitting strength and specific fracture energy of building materials, combinations of building materials and composites wedge splitting method; 2011.

[27] Hendriks MAN, de Boer A, Belletti B. Guidelines for nonlinear finite element analysis of concrete structures. Rijkswaterstaat Centre for Infrastructure, Scope: Girder Members, Report RTD:1016:2012; 2012.
[28] Cusatis G, Pelessone D, Mencarelli A. Lattice discrete particle model (LDPM) for failure behavior of concrete. I: theory. Cement Concrete Composites. 2011;33(9):881-890.

[29] Cusatis G, Pelessone D, Mencarelli A. Lattice discrete particle model (LDPM) for failure behavior of concrete. II: calibration and validation. Cement Concrete Composites. 2011;33(9):891-905.

[30] Filippou FC, Constantinides M. FEDEAS Lab getting started guide and simulation examples. Technical Report NEESgrid-TR22; 2004.

[31] fib, Model Code 2010, 2011. 